\title{
Bragg Coherent Diffraction Imaging for In Situ Studies in Electrocatalysis
}

\author{
Rafael A. Vicente, Itamar T. Neckel, Subramanian K. R. S. Sankaranarayanan, José Solla-Gullon, \\ and Pablo S. Fernández*
}

Cite This: ACS Nano 2021, 15, 6129-6146

ACCESS | Lلll Metrics \& More | 回 Article Recommendations | St Supporting Information

ABSTRACT: Electrocatalysis is at the heart of a broad range of physicochemical applications that play an important role in the present and future of a sustainable economy. Among the myriad of different electrocatalysts used in this field, nanomaterials are of ubiquitous importance. An increased surface area/volume ratio compared to bulk makes nanoscale catalysts the preferred choice to perform electrocatalytic reactions. Bragg coherent diffraction imaging (BCDI) was introduced in 2006 and since has been applied to obtain 3D images of crystalline nanomaterials. BCDI provides information about the displacement field, which is directly related to strain. Lattice strain in the catalysts impacts their electronic configuration and, consequently, their binding

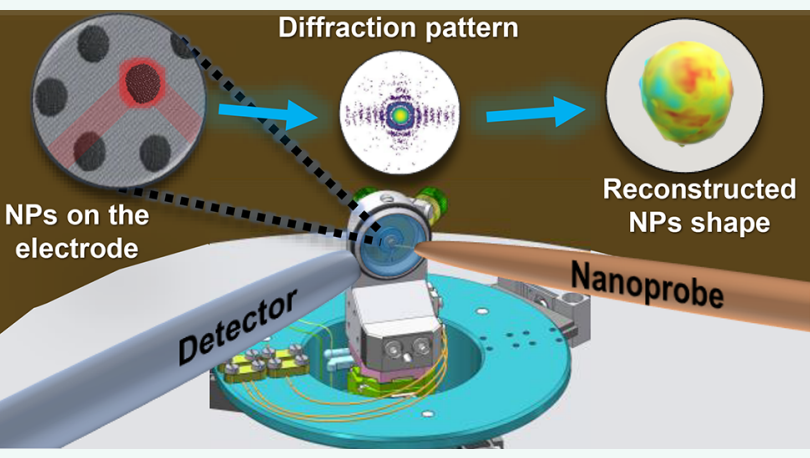
energy with reaction intermediates. Even though there have been significant improvements since its birth, the fact that the experiments can only be performed at synchrotron facilities and its relatively low resolution to date $(\sim 10 \mathrm{~nm}$ spatial resolution) have prevented the popularization of this technique. Herein, we will briefly describe the fundamentals of the technique, including the electrocatalysis relevant information that we can extract from it. Subsequently, we review some of the computational experiments that complement the BCDI data for enhanced information extraction and improved understanding of the underlying nanoscale electrocatalytic processes. We next highlight success stories of BCDI applied to different electrochemical systems and in heterogeneous catalysis to show how the technique can contribute to future studies in electrocatalysis. Finally, we outline current challenges in spatiotemporal resolution limits of BCDI and provide our perspectives on recent developments in synchrotron facilities as well as the role of machine learning and artificial intelligence in addressing them.

KEYWORDS: Bragg coherent diffraction imaging, electrochemistry, electrocatalysis, strain, in situ experiments, X-ray diffraction, fourth-generation synchrotron, computational experiments, single-nanoparticle experiments

\section{INTRODUCTION}

Electrocatalysis is a key field for the sustainable development of economy, mainly through its contributions in the conversion and storage of energy. Some of the most important examples of electrocatalytic systems are (i) fuel cells, which can generate electric energy through a highly efficient process ${ }^{1,2}$ (for instance, PEM fuel cells, which oxidize $\mathrm{H}_{2}$ in their anode and reduce $\mathrm{O}_{2}$ in their cathode, ${ }^{3}$ have as a main drawback the slow kinetics of the oxygen reduction reaction (ORR); ${ }^{4}$ thus, there have been for decades an intense search for more efficient catalysts (generally nanomaterials) to run this reaction); and (ii) electrolyzers for the generation of dense energy carriers such as high purity hydrogen, ${ }^{5-7}$ which can be used as fuel in PEM fuel cells or to produce ammonia among many other uses. The main drawback of the well-known water splitting reaction is the water oxidation to form $\mathrm{O}_{2}$, and there is a vast literature about nanomaterials to be applied for the oxygen evolution reaction (OER). ${ }^{4}$ Furthermore, in the frame of galvanic cells, the conversion of $\mathrm{CO}_{2}$ to value-added alcohols and hydrocarbons has become a hot topic in the past decade. $^{8}$

All of these devices (all kinds of fuel cells and electrolyzers) and the corresponding reactions need suitable catalysts to achieve the highest possible rates and selectivities. The catalyst's activity and the reaction selectivity depend on many experimental factors, namely, the following: (i) the

Received: February 4, 2021

Accepted: March 18, 2021

Published: April 1, 2021

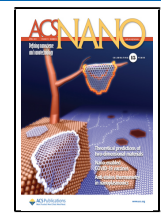




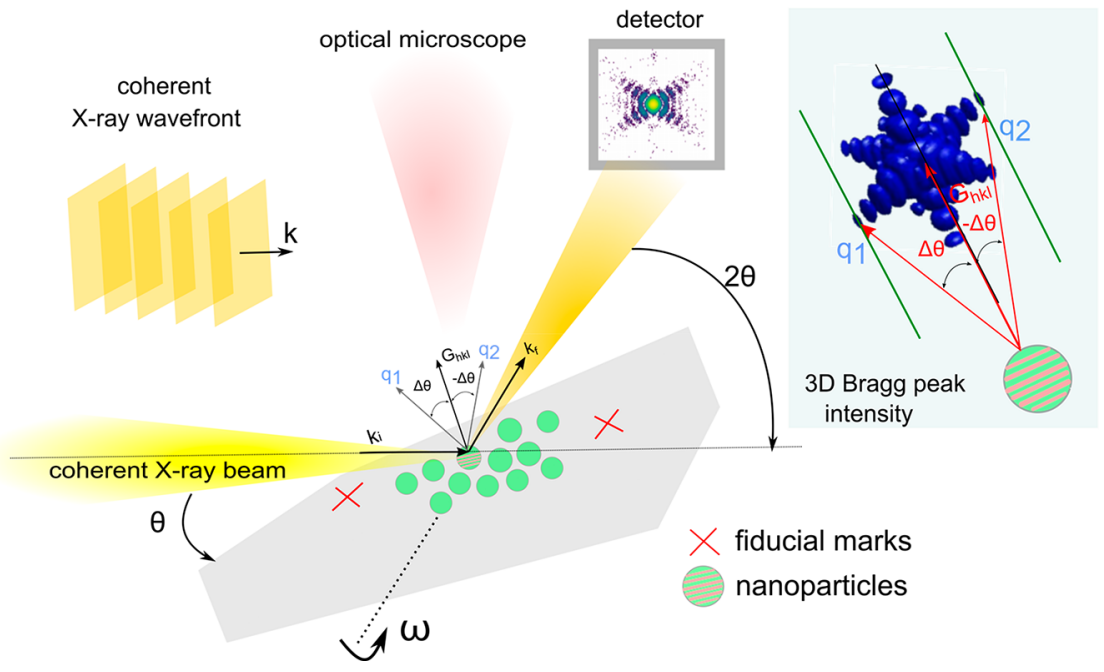

Figure 1. Scheme used in a typical BCDI data acquisition. Isolated NPs (green with red dashes) are illuminated by a coherent X-ray beam in a conventional symmetric Bragg geometry. The scattering vector denoted by $G_{h k l}$ is perpendicular to the crystalline planes investigated. $k_{\mathrm{i}}, k_{\mathrm{f}}$, and $G_{h k l}$ (also $q_{1}$ and $q_{2}$ ) represent the incoming, diffracted, and transfer momentum vector, respectively. By rotating the sample around the $\omega$ axis, the fringes around the center of the Bragg peak are collected. Then, the results collected at all of the $\omega$ angles are stitched together to give the Bragg peak intensity in 3D (in blue). Several diffraction patterns are collected around $\omega$ (from $q_{1}$ to $q_{2}$, steps of $0.002-0.01^{\circ}$ ). An illustration of a coherent wavefront is given on the panel. The scheme also shows the position of the optical microscope which helps to find the fiducial marks on the sample represented by red " $X$ ".

reaction temperature; (ii) the nature of the electrode, electrolyte, and solvent; and (iii) the design of the electrochemical reactor, etc. The nature of the catalyst is determined by the kind of atoms that form them (Is it made of Pt? Is it pure $\mathrm{Pt}$ or has another kind of atom?), their structure (Is it crystalline or amorphous? If it is crystalline, which is its structure?), and if it is a bulk material or a nanomaterial, etc. Irrespective of if it is a nanomaterial or a bulk material, its electrochemical behavior will also depend on the arrangement of the atoms at the surface of the catalyst. For the case of nanomaterials, several times the atom's arrangement is closely related to the particle shape. ${ }^{9}$ Finally, if the nanomaterial is small enough, all of its properties depend on the size. ${ }^{10}$

To understand the performance of nanomaterials in an electrocatalytic process, it is important to study their properties in the presence of the electrolyte. Thus, in situ experiments are becoming mandatory to understand the properties of nanomaterials and how these properties are affected by the electrochemical potential, the electrolyte, temperature, light power (in photochemistry), and energy, etc.

In this context, we believe that Bragg coherent diffraction imaging (BCDI) together with computational experiments will become an extremely powerful tool to get detailed information about electrocatalytic processes. This technique gives 3D images of individual NPs and grains, also providing information about the displacement field, which is a parameter rather abstract for electrochemists. In addition, computational experiments permit us to connect it with lattice strain and defects under in situ conditions, which are well-known features that appear in the structure of the electrocatalysts affecting their activity and selectivity. ${ }^{11}$

$\mathrm{BCDI}$ is a promising technique but still not very well-known by the scientific community because of its historical relatively low resolution (compared to electron microscopies and scanning probe techniques) and because the experiments can be only performed at a few synchrotron facilities in the world. However, recent results obtained by some of us ${ }^{12}$ in the MAX
IV facility in Sweden ${ }^{13}$ show that we are striding toward the real-time in situ observation of $3 \mathrm{D}$ images of nanomaterials with size well-below $100 \mathrm{~nm}$. Further, the launch of the SIRIUS facility in Brazil $^{14}$ presents opportunities for the development of the technique and for several other fields of science and technology.

Here, we discuss the fundamental aspects of BCDI using an affordable language for the broad electrochemistry community. We start with a detailed introduction to this powerful X-ray imaging modality followed by highlighting some of the most important computational tools that have been coupled with BCDI to extract information about the underlying 3D structural and dynamical evolution of particles undergoing catalysis. We discuss electrocatalytically relevant features such as lattice strain, which could be measured by BCDI. Since strain in nanomaterials can highly impact their electrocatalytic behavior, we discuss how the activity and selectivity can be affected by this parameter and studied by BCDI. Next, we present representative successful BCDI experiments in the field of electrochemistry and heterogeneous catalysis. We also highlight some of the most important developments enabled by BCDI in the electrocatalysis. Finally, we provide our perspective on the current spatiotemporal challenges in BCDI and the recent developments in synchrotron facilities as well as the role of data science/machine learning toward addressing them.

\section{FUNDAMENTAL ASPECTS OF BCDI}

Coherent Flux at Third and Fourth Synchrotron Generations. BCDI is a lens-less imaging technique exploiting over the past 20 years the coherence on high brilliant third-generation synchrotrons. As a consequence of the low source's emittance, ${ }^{15}$ reaching to a few units of nm.rad (source size $X$ angular divergence), ${ }^{16}$ these machines can emit an X-ray beam with characteristics similar to a laser-like source; i.e., the X-ray wavefronts are strongly correlated (see Figure 1). Conversely, the sun (or a lamp), for example, represents an 
a)

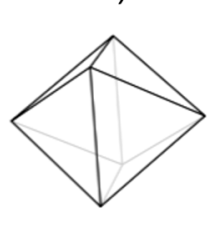

b)
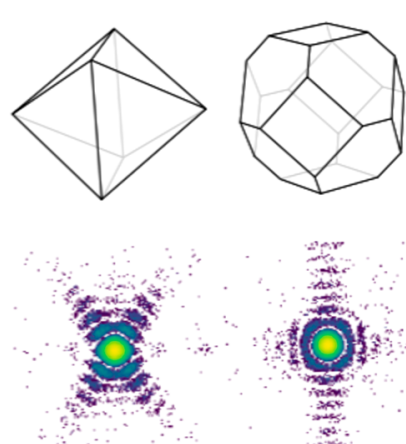

c)
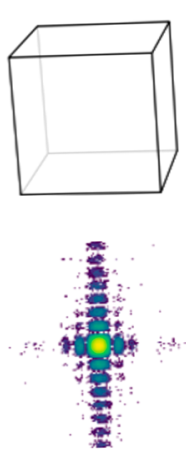

d)

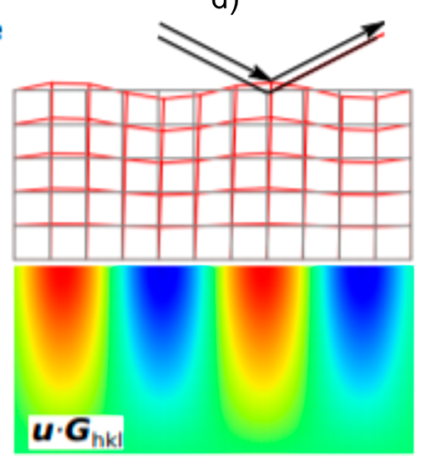

Figure 2. Basic principles of BCDI. $(\mathrm{a}-\mathrm{c})$ Simulated diffraction patterns for three strain-free model particles. The recorded fringe pattern depends on the particle shape, with fringes seen in the directions of any surface facets. (d) Lattice displacement causes a phase shift of the diffracted beam, which is sensitive only to the component of displacement parallel to $\mathrm{G}_{h l k}$, perpendicular to the diffracting planes. Image courtesy of Dr. Alexander Björling.

incoherent source chaotically emitting light, where the emitters have no memory about the phase emission. In a simple way, the brilliance of a synchrotron source describes how concentrated (collimated) the X-ray beam is. Additionally, coherence is associated with (responsible for) interference (fringes) phenomena also at the nanoscale, something similar to the well-known Young's experiment.

In contrast with the third generation, the fourth-generation synchrotrons, also called the fourth generation, are very low emittance machines (order of $200 \mathrm{pm} \cdot \mathrm{rad}$ ), ${ }^{17-19}$ leading to an ultrabrilliant and coherent source. Hence, exploiting an optics that preserves the coherent flux from the source, a full coherent beam can be focused on the sample with a coherent photon flux $10^{2}$ to $10^{4}$ times higher than that obtained in the thirdgeneration synchrotrons. For example, at the NanoMAX beamline (MAX IV) the coherent flux exceeds $10^{11}$ photons/ $\mathrm{s}$ for energies from 6 to $10 \mathrm{keV}^{20}$ and it is expected, for the same energy range, to exceed $10^{12}$ photons/s for the Carnaúba beamline (SIRIUS). ${ }^{21}$ Arguably, a milestone of coherent flux is achieved in the fourth-generation machines thanks to the extremely high brightness, which delivers a full coherent beam at the sample. The high coherent flux combined with low noise, fast detection systems and high stable end-station/ instruments, can drastically decrease the acquisition time and have the potential to push the resolution to the atomic scale in imaging experiments. ${ }^{22}$

Performing BCDI Experiments: Sample Preparation and Requirements. The experimental conditions and requirements to perform a BCDI experiment can be summarized into three groups: (i) Sample characteristics, (ii) sample preparation, and (iii) diffraction pattern acquisition. Initially, to perform a BCDI experiment, the first requirement is to have a crystalline sample fully illuminated and stable in front of the coherent beam. If the sample has a noncrystalline phase, only relevant information about the crystalline fraction is obtained. Moreover, because the X-ray beam is very small, typically with a focal spot from $30 \mathrm{~nm}$ to $1 \mu \mathrm{m}$, special sample preparation is required since the $\mathrm{X}$-ray beam will shine on only one or a few crystals. Thus, a previous characterization of the sample by electron microscopy is important to obtain the morphology/shape and the crystalline orientation (which Bragg peaks are accessible) of the sample or object to be investigated by BCDI. In addition, for some experiments, it could be highly recommended to define a region of interest
(ROI) in the sample holder to easily localize a target particle that we previously observed by electron microscopy. A common approach is to generate marks (known as fiducial marks) in the sample (or substrate) by using focused ion beam (FIB) or other lithography method.

BCDI is a technique essentially applied to obtain $3 \mathrm{D}$ deformation maps and defects. Due to its versatility, it has been applied on a wide range of sample environments (catalysis, electrochemistry, and nanodevices, among others). The acquisition of the data consists of recording diffraction patterns by rotating the sample in front of a coherent beam (see Figure $1)$. First, the sample is mounted on the rotation center of a precise rotation stage, where the X-ray beam was previously aligned by combining several translation stages. Nanoprobe end-stations usually include optical microscopes with a spatial resolution of a few micrometers, which help to locate the fiducial marks and consequently the sample or a specific ROI.

After selecting the crystal or feature of interest, using the Bragg's law $\left(2 d_{h k l} \sin \Theta=\lambda\right)$, a Bragg's reflection is selected by moving the sample to a specific angle with respect to the coherent beam denominated Bragg's angle $(\Theta)$. Consequently, the detector should be moved to $2 \Theta$. Considering as a simple example the platinum, a material widely applied in electrocatalysis and studied by BCDI, the (111) Bragg reflection is located at $\Theta=18.75^{\circ}$ with respect to the incident beam. Thus, to record the diffraction pattern the detector should be placed at $2 \Theta=37.5^{\circ}$. With the Bragg's reflection selected, the BCDI data acquisition is performed by slightly varying the angle $\Theta$ between the sample and the beam up to $\pm 1^{\circ}$ (called the rocking curve) at steps typically between $0.002^{\circ}$ and $0.01^{\circ}$, whereas the detector is kept at the $2 \Theta$ position. Typically, in one rocking curve, a large number of diffraction patterns are recorded between $q_{1}$ and $q_{2}$, which are then stitched together to give the 3D Bragg peak intensity (see the light-blue inset), i.e., the key quantity of this imaging technique. Considering that the measurement is performed using a highly intense beam, it is important to monitor if any structural or mechanical change on the sample is due to the beam incidence and/or to the phenomena that is being studied. Structural changes due to the incidence of radiation are known as radiation damage. ${ }^{23}$ For instance, in a typical experiment in heterogeneous catalysis, a possible approach could be to shine the particle with the beam in an inert atmosphere to monitor if the beam induces any change in the particle in a condition where it is 


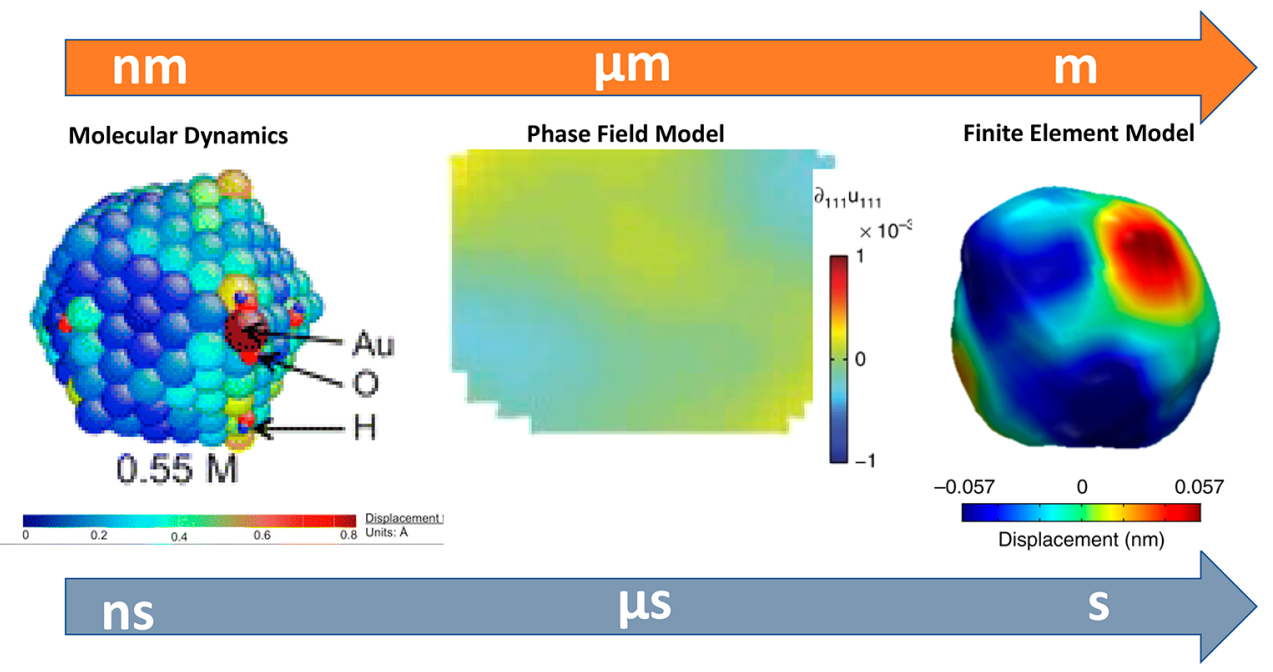

Figure 3. Multitude of different simulations spanning a broad range of length and time scales utilized to complement the BCDI experiments. (From left to right) Local strains measured in single NPs can be modeled using reactive molecular dynamics (RMD) simulations. RMD reveals the pathway for local strain generation in the gold lattice via chemisorption of hydroxyl ions. Adapted in part with permission from ref 56. Copyright 2016 American Chemical Society. The $\partial_{111} u_{111}$ strain distribution computed by the phase-field model during the hydriding phase transformation in individual palladium NPs. Adapted in part with permission from ref 59. Copyright 2015 Springer Nature. The FEA predictions for a $220 \mathrm{~nm}$ Pt nanocrystal in response to adsorption induced external force generated during the catalytic methane oxidation process. Adapted in part with permission from ref 48. Copyright 2018 Springer Nature.

stable. By mechanical change, we mean a translation or/and rotation of the particle caused by the beam energy. If the particle changes randomly its orientation, the result obtained will be seriously compromised. This problem can be faced by increasing the interaction between the particle and the substrate or by computational methods. ${ }^{24}$ Besides, continuous scanning (rocking curve) was proposed to decrease the time acquisitions and mitigate the drawbacks related to the beam-sample interaction, especially during in situ experiments. ${ }^{25}$ Apart from the requirements for the NP, the stability and precision of the rotation stages must be maximized, to get the best possible resolution of the final images.

Diffractogram, the Image and the Strain Map. In BCDI, shape and strain images of single NPs can be obtained by analyzing one or more crystal diffraction peaks. Just as bulk crystals produce discrete diffraction spots at positions which satisfy Bragg's law, such diffraction can be observed from single NPs if the incident X-rays are intense and tightly focused. While bulk crystals produce narrow and practically discrete peaks, small crystals give rise to broader diffracted beams. This is a familiar phenomenon in X-ray powder diffraction and wellknown in the field of electrocatalysis, where the finite-size effect described by Scherrer's equation is used to estimate crystallite sizes from peak widths. While such powder patterns arise from averaging over many particles, orientations, and shapes, single NPs instead give rise to broadened diffraction patterns with well-defined interference fringes, also called speckles. ${ }^{26}$ Panels a-c of Figure 2 illustrate this phenomenon with simulated diffraction patterns at the Bragg condition from faceted NPs of different shapes. These fringes can be analyzed in 3D (see Figure 1) through computational processes involving interactive algorithms, ${ }^{27,28}$ known as phase retrieval ${ }^{29}$ algorithms yielding three-dimensional reconstruction of the particle's shape and internal strain fields.

The mathematics of BCDI is well-established and has been clearly explained elsewhere. ${ }^{30-32}$ Our aim here is to provide a basic geometrical description of BCDI experiments for non- expert users. Therefore, an important question to address is, How are the morphology and strain of a NP obtained from the measured 3D Bragg peak intensity? As displayed before (see Figure 1), every Bragg peak of a single nanocrystal is decorated with a fringe pattern that encodes its shape and phase. If the particle is uniform (unstrained), the phase is constant or flat. On the other hand, real crystals are naturally strained and then the atoms in the crystal occupies positions slightly out of the ideal position, yielding to a complex electronic density whose image is composed by an amplitude and phase.

The success of BCDI relies on the recovery of this complexevaluated electron density, mathematically expressed as $\tilde{\rho}=$ $\rho e^{i \varphi} .{ }^{33}$ Intuitively, the magnitude $(\rho)$ of this complex function gives the morphology (the real space electron density) of the particle, and the retrieved phase $(\varphi)$ encodes the lattice distortion. Hence, the electronic density map provides the displacement field, which is intimately connected to the complex-electronic density phase by $\varphi(\vec{r})=\overrightarrow{G_{h k l}} \cdot \vec{u}(\vec{r})$, where $\vec{u}(\vec{r})$ measures how dislocated the atoms are from their theoretical position $\left(\vec{u}=\vec{r}-\vec{r}_{0}\right)$, what is called the displacement field. The measured Bragg reflection gives the $G_{h k l}$. This is experimentally useful, since the lattice displacement field of a crystal is closely related to the strain imposed on it by, for example, surface processes. To see how this sensitivity arises, consider Figure $2 \mathrm{~d}$, where the black grid represents an undisturbed lattice, while the red grid is a lattice which is arbitrarily perturbed at the surface. When an incident wave is diffracted by the particle, the wave scattered from the disturbed lattice will be out of phase with waves scattered from the undisturbed lattice by some difference $\varphi$. The particle's phase image provides the displacement field image or a strain field image, depending on the approach. The strain (3D map) can be obtained by the gradient of the displacement field. A complete discussion and the theory involving the relationship between strain and displacement field (fundamentals of elasticity) can be found elsewhere. ${ }^{34,35}$ 
Delving deep in terms of the reciprocal lattice, familiar to crystallographers, there is a three-dimensional intensity distribution about each lattice point $(h, k, l)$, given by the squared magnitude of the three-dimensional Fourier transform of the particle's complex electron density (intensity = I $\left.\left.\operatorname{FFT}(\tilde{\rho})\right|^{2}\right)$, computed into the phase retrieval algorithms by the fast Fourier transform (FFT). Experimentally, the detector measures only the intensity losing the phase information ("phase problem"). Hence, the scattering amplitude is the FFT of $\tilde{\rho}$ (amplitude $=\operatorname{FFT}(\tilde{\rho}))$, or simply the Fourier transform of the crystal shape. In BCDI there is no direct imaging in the real space; then, the inverse of the Fourier transformation $\mathrm{FFT}^{-1}$ of the amplitude should be calculated after retrieving the phase information, to obtain real space information (crystal shape). Since the intensity is adequately "oversampled" (NyquistShannon sampling theorem), meaning that each interference fringe surrounding the Bragg peak should be recorded on the detector by at least three pixels (or more), ${ }^{36,37}$ the measured intensity allows reconstructing with high quality the complexevaluated electron density (amplitude and phase) in 3D.

Besides coherence, BCDI also explores the penetration power of X-rays, allowing 3D imaging of the morphology, strain fields, and internal defects in nanocrystals with resolutions close to $10 \mathrm{~nm}^{38}$ that is quite moderated compared to, for example, electron microscopy, where the resolutions can achieve sub-angstrom in transmission mode, ${ }^{39}$ although the penetration depth of the electron beam is very small, requiring a very sophisticated and, in general, a destructive sample preparation. As with any imaging technique, BCDI has its limitations in spatial resolution. At higher angles (higher order reflections) the intensity of a Bragg peak decreases proportional to, and also radially decays out of, the center of the peak, decreasing the photons counting on the detector and, consequently, reducing the intensity of the fringes. Overall, the resolution in BCDI depends on how far in the reciprocal space (light-blue inset of Figure 1) the fringes of a Bragg reflection can be measured with significant intensity, which experimentally is greatly limited by the detection system, being important the detector area, dynamic range (counting rate per pixel), and signal-noise ratio. Furthermore, the mechanical stabilities of the end-station (the instruments) and sample also play an important role in the quality of the final $3 \mathrm{D}$ images. $^{40}$

\section{COMPUTATIONAL EXPERIMENTS TO EXTRACT REAL AND RECIPROCAL SPACE INFORMATION}

There exists a multitude of different simulation techniques spanning a broad range of length and time scales-these have been utilized to complement the BCDI experiments (see Figure 3). ${ }^{41-44}$ These simulations provide direct real space information on the evolution of lattice strain and displacements. ${ }^{45-48}$ One can easily compute diffraction patterns from the simulated trajectories to make suitable comparisons with the experimentally derived information in the reciprocal space. ${ }^{41-44,49}$ As such, the combination of simulations and experiments allows for efficient and enhanced information extraction about the underlying catalytic processes (Figure 3 ). We present a brief overview of some of these different methods commonly employed to understand the electrocatalytic processes and the associated lattice strain induced in the nanoscale structures.

Electronic Structure and Atomistic Scale Modeling. At the atomistic scale, molecular dynamics simulations are commonly employed to study the dynamical evolution of the NPs. ${ }^{50-53}$ There are various flavors of molecular dynamics: although $a b$ initio MD (AIMD) $)^{54}$ captures the bond formation and bond breakage processes, it is limited by the inevitability of dense linear algebra in density functional theory (DFT), which means that scaling to larger length scales beyond a few 100 atoms is a major hurdle. ${ }^{55}$ While an elaborate simulation of the electrocatalytic process to explicitly include solvent effects is not tractable using first principles yet, their high accuracy is often advantageous in addressing individual problems such as estimating the reaction barriers and understanding pathways for phase transformations. ${ }^{55}$ Classical MD, within the BornOppenheimer framework, allows for simulations of phenomena that span over nanoseconds in time scale and several tens of nanometers in length scale. Classical MD is, however, often limited by the accuracy of the interatomic potentials and restricted to nanometer length and nanosecond time scales. Reactive MD simulations have become quite popular and are being widely used to simulate chemical reactions while concurrently capturing the structure and dynamical evolution of the catalyst. ${ }^{47,48}$ These reactive $\mathrm{MD}$ simulations enable larger ensembles to be calculated, and as such these simulations have been used to model electrocatalytic processes while accounting for solvent and interfacial effects to be reliably captured. ${ }^{56}$

The goal of such simulations is often to investigate if there are any atomic-level processes that can create large local displacements in the nanocrystal lattice involved in an electrochemical process and to provide atomistic insight for the reaction-related forces on the NPs. For instance, Ulvestad et al. have explored gold-catalyzed ascorbic acid decomposition using reactive MD simulations. ${ }^{56}$ Ascorbic acid decomposition pathway in the presence of dissolved oxygen was explored, and it was shown that the pathway involves co-physisorption of a water molecule and the acid, and dissociation of the adsorbed water molecule into $\mathrm{H}^{+}$and $\mathrm{OH}^{-}$ions aided by an oxygen atom on the acid molecule. The dissociated $\mathrm{OH}^{-}$ion chemically binds to the corner site that induces a strain on the gold lattice, which can be compared to the measured lattice strain in BCDI experiments. Reactive MD was also used to probe the reaction mechanism of methane oxidation on $\mathrm{Pt}^{48} \mathrm{It}$ was shown the contraction at the edges of the Pt particle arises from dissociated $\mathrm{O}$ atoms and becomes stronger when $\mathrm{CH}_{4}$ molecules bond to the dissociated $\mathrm{O}$ atoms during the chemical reaction with $\mathrm{CH}_{4}$. The simulations explained the BCDI measured deformation field distribution arising from the interaction forces between the reactants and the Pt catalyst (see more details of this work in BCDI Applied to Electrochemistry and Heterogeneous Catalysis).

Mesoscale Modeling. Phase field and kinetic Monte Carlo (KMC) simulations have been used to simulate the mesoscopic behavior and link the atomistic simulations with continuum methods. ${ }^{57}$ Phase field models based on the CahnHilliard equations have been applied to probe mesoscale electrochemical processes appropriately accounting for a variety of effects, including surface wetting, elastic energy, and chemical kinetics. ${ }^{58}$ In these models, the free energy of a given particle undergoing the electrochemical process is described by the free-energy functional: 


$$
\begin{aligned}
F= & \int_{V}\left\{f+\frac{1}{2} \sigma_{i j} \epsilon_{i j}^{\mathrm{el}}+\frac{1}{2} \kappa\left|\nabla_{p}\right|^{2}\right\} \mathrm{d} V \\
& +\int_{A}\left\{f^{S}\left[1+\epsilon_{i i}^{S}\right]+\frac{1}{2} \sigma_{i j}^{S} \epsilon_{i j}^{\mathrm{el}, S}\right\} \mathrm{d} A
\end{aligned}
$$

where $f$ is the free-energy density containing both the enthalpy and the entropy, $\frac{1}{2} \sigma_{i j} \epsilon_{i j}^{\mathrm{el}}$ is the elastic energy density, $p$ is the local fraction of the constituent phase, and $\frac{1}{2} \kappa\left|\nabla_{p}\right|^{2}$ is the gradient energy density. Note that the elastic energy is typically associated with the lattice mismatch between the precipitating phase (e.g., hydride phase) and the matrix (e.g., palladium nanocubes). ${ }^{59}$ The phase field model serves as a basis for quantitative understanding of the influence of elastic energy, interface energy anisotropy, and interface mobility anisotropy, and the above equation captures their relative contributions. One generally assumes instantaneous elastic relaxation relative to diffusion, and the displacement field vector $\vec{u}_{i}$ is solved quasi-statically. Along with the chemical potential of the species, one solves the governing equations for volume and surface to describe the strain distributions in the particle. Such a $3 \mathrm{D}$ phase field model was used to interpret the BCDI experiments exploring hydriding phase transformation in individual palladium nanocubes. ${ }^{99}$ It was shown that the phase transformation dynamics involves nucleation and propagation of a hydrogen-rich region that depends on absolute time (aging) and involves intermittent dynamics (avalanching). The BCDI measured strain fields were consistent with an initial hydrogen enrichment in the corners of the Pd nanocube followed by the nucleation of a hydrogenrich region at the corner of the nanocube. In general, these simulations enable an understanding of phase transitions in mesoscale reactive environments.

KMC represents another popular class of mesoscale simulation method to probe reactive dynamics and the associated structural evolution. ${ }^{60-62}$ The KMC simulations are stochastic in nature and model the physical processes based on a predefined rate catalog. For each of the physical processes, one computes the occurrence probability on the basis of knowledge of the activation barriers and the attempt frequencies. ${ }^{63-66}$ The system is then propagated by selecting the occurrence process using a random number, and subsequently the selection probabilities are updated according to the new system configuration. An advantage of KMC simulations over phase field is that atomistic details are preserved. However, it should be noted that KMC simulations depend on a predefined library of elementary steps, which can often impose serious limitations. Nonetheless, KMC simulations have been applied to a broad class of electrochemical applications including Li-ion batteries, solid electrolyte interphase (SEI) passive layer formation, electrochemical dealloying, and solid oxide fuel cells. ${ }^{67,68}$

Continuum Scale Models. At the continuum scale, the governing equations for modeling the electrodes and electrolyte involve Ohm's law, and basic transport laws, depending on the mobile species in each phase. Typically, the governing relations relate flux to mobile species concentration and electrical potential, while assuring that mass and charge conservation laws are obeyed. ${ }^{69,70}$ Ohm's law is sufficient to model regions in which electrons are the only mobile species. For multiple mobile ionic species, the Nernst-Planck equation, relating flux to mobile ionic species concentration and electrical potential, must be used. ${ }^{71}$ This accounts for diffusion, migration, and convection, with appropriate assumptions regarding concentrations, i.e., electrolyte theory. For example, to model electrode kinetics and mass transport in an electrochemical system comprised of lithium ions and electrons, the kinetic equations are given by ${ }^{72-74}$

$$
\begin{aligned}
& \frac{\partial n_{\mathrm{Li}}}{\partial t}=\nabla \cdot\left(D_{\mathrm{Li}} \nabla n_{\mathrm{Li}}\right)+\nabla \cdot\left(\frac{D_{\mathrm{Li}} z F n_{\mathrm{Li}}}{R T} \nabla \phi\right) \\
& \frac{\partial \rho}{\partial t}=\nabla \cdot\left(\kappa_{T} \nabla \phi\right)+\nabla \cdot\left(\frac{D_{\mathrm{Li}} z \mathrm{~F}}{R T} \nabla n_{\mathrm{Li}}\right)
\end{aligned}
$$

The first equation represents the rate of change in the number density of $\mathrm{Li}$ ions, and the second one represents the charge density change with time. In the above equation, $D_{\mathrm{Li}}$ is the intrinsic diffusivity of $\mathrm{Li}$ ions and depends on the activity coefficient. The above equation assumes that interactions between electrons and lithium ions are limited to the active material-electrolyte interface, as well as no local charge accumulation $\left(\frac{\partial \rho}{\partial t}=0\right)$. To model interfacial reactions and dynamics, one typically assumes that the rate of transfer of ions (example, $\mathrm{Li}^{+}$in $\mathrm{Li}$-ion battery or $\mathrm{Cl}^{-}$in the case of corrosion) from the electrolyte to the active material (battery electrode or corroding oxide surface) is controlled by the local deviation of the surface potential with respect to its equilibrium value, as given by the Butler-Volmer relation which depends on the relative rates of the forward rate of the anodic process and backward rates of the cathodic process. ${ }^{69,70}$ The finite element method (FEM) calculations thus give spatial and temporal predictions of the structure as well as the surface concentration distributions for each reactant, product, and intermediate species associated with the proposed reaction mechanism. While details of the nanoscopic processes are not included in such models, a key advantage of these continuum models is that they allow more direct comparisons of the model predictions with experimental observations. In several recent studies, the FEA models are informed by reactive molecular dynamics (RMD). ${ }^{48,56}$ For instance, the force exerted by an adsorbed $\mathrm{O}$ atom on a $\mathrm{Pt}$ atom was determined from the $\mathrm{RMD}$ simulation and was applied in an FEA model and over a surface coverage calculated using the ratio of the adsorbed methane to oxygen atoms. ${ }^{48}$ The resulting displacement distribution from experiments and RMD informed FEA were compared for a 220 $\mathrm{nm}$ Pt catalyzing a methane oxidation process. Such multiscale approaches allow for a comprehensive understanding of the reaction mechanisms as well as the resulting lattice strain, which could be directly compared with BCDI reconstructions.

\section{BCDI APPLIED TO ELECTROCHEMISTRY AND HETEROGENEOUS CATALYSIS}

BCDI has been applied in several fields of science and technology including the study of NPs in gener$\mathrm{al}^{12,24,25,30,59,75-110}$ zeolites, ${ }^{111,112}$ heterogeneous catalysis, $^{48,56,113-120}$ batteries, ${ }^{121-127}$ supercapacitors dielectrics, $^{128-131}$ nanowires, ${ }^{32,132-142}$ minerals, ${ }^{143-147}$ alloys and dealloying, ${ }^{148-152}$ nanorods, ${ }^{43,153-158}$ proteins, ${ }^{159-161}$ thin films, ${ }^{38,41,44,162-164}$ and other materials. ${ }^{165,166}$ Table S1 in the Supporting Information summarizes all of the literature (at least to our knowledge) containing BCDI experiments, detailing which was the material studied and the data obtained by BCDI. 
(a) Initial State

(b) $30 \mathrm{~s}$ at 0.4 Volts

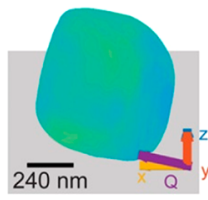

Volume $=\mathrm{V}$

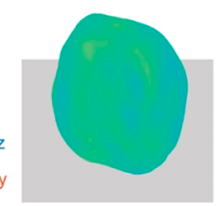

Volume $=\mathrm{V}_{0}$ (c) $60 \mathrm{~s}$ at 0.4 Volts

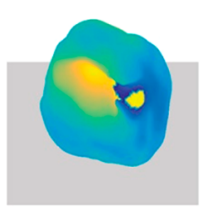

Volume $=0.88 \mathrm{~V}$ (d) $90 \mathrm{~s}$ at 0.4 Volts

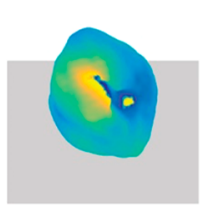

Volume $=0.65 \mathrm{~V}_{0}$ (e) $120 \mathrm{~s}$ at 0.4 Volts

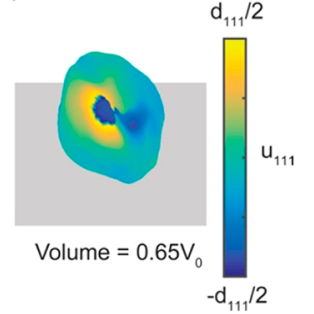

Figure 4. Three-dimensional view of a single particle and lattice displacement evolution during the dissolution at $0.4 \mathrm{~V} v \mathrm{Ag} / \mathrm{AgCl}$ reference electrode. The first image at the left shows also the scattering vector $(\mathcal{Q})$ and the lab frame axes $(x, y, z)$. Also shown are how both the volume of the NP and the lattice displacement field change over time at constant potential due to the oxidation of $\mathrm{Ag}$ to $\mathrm{Ag}^{+}$. The color bar for the lattice displacement applies to all images. Although the particle loses Ag atoms from all of the surface, there is more relative dissolution from the corner, where the changes in the displacement field are higher. Reprinted with permission from ref 89 . Copyright 2017 American Chemical Society.

Instead of discussing all of the research articles where BCDI has been used, in this section we describe in more detail the findings in works performed in electrochemical ambient and some results in heterogeneous catalysis, which show how promising this technique is to study electrocatalytic materials.

One of the most important topics in electrochemistry is energy storage. Several research articles have been published in the most recent decades about batteries (Table S1), including reviews about the application of BCDI in this field. ${ }^{167-169}$ Table S1 shows several works in the field of batteries, studying materials with sizes between 300 and $1000 \mathrm{~nm}$. Materials used in batteries are generally orders of magnitude bigger than those used in electrocatalysis, where in most of the cases high area/ volume ratio is desirable, what certainly explains the difference in the presence of the technique in these fields.

Shpyrko's group made important contributions to the study of batteries using BCDI in in situ and in operando conditions. They studied high capacity and high voltage lithium-ion batteries, focusing on LNMO $\left(\mathrm{LiNi}_{0.5} \mathrm{Mn}_{1.5} \mathrm{O}_{4}\right)$ spinel's cathodes. $^{122-127}$ For example, they measured an octahedral $400 \mathrm{~nm} \mathrm{NP}$ and followed the central location of the Bragg peak (which is connected to the lattice constant) and its asymmetry (which is connected to the particle strain) at different applied potentials or, equivalently, at different lithium charges and showed that during the charge-discharge process the strain is inhomogeneous through the particle and that it is minimized at full lithiation, giving important insight about the chargedischarge mechanism. ${ }^{127}$ It is important to notice that the group showed the inhomogeneity of the strain (which is connected to an inhomogeneous lithiation), in a previous article. $^{124}$ They also studied by BCDI the dynamics of the charge/discharge of LNMO and found that during the discharge the material presents two phases, while during charge it is mainly formed by a solid solution. ${ }^{122}$ BCDI also sheds light into disconnection events, which are an important source of capacity loss. ${ }^{125}$ The authors followed the location of the Bragg peak during the charge/discharge process and observed a constant position at a given time independently of the electrode charge, a direct indication of NP disconnection. By analyzing 3D strain evolution, they detected the formation of low ionic conduction interphase, which leads to a decrease in capacity. Defects and dislocations play a key role in several electrochemical processes. For example, the density and kind of defects in a surface determine the electrocatalytic behavior of a material. Defects are also important in the field of batteries and can also be tracked by BCDI. ${ }^{126}$ The authors follow dislocations in a single NP by mapping the displacement field.
The defect type generates a different relation between the displacement field magnitudes and the azimuthal angle. In this specific work, the authors found a linear relationship between the displacement field and the azimuthal angle, characterizing an edge dislocation. The same authors performed a BCDI experiment using LRLOs (lithium-rich layered oxide) cathode, more precisely $\mathrm{Li}_{1.2} \mathrm{Ni}_{0.133} \mathrm{Mn}_{0.533} \mathrm{Co}_{0.133} \mathrm{O}_{2}$. Tracking the intensity of the displacement field, the authors were able to follow the nucleation of a dislocation network (perturb the oxygen layer sequence) and connect the phenomena with the voltage fade in these materials. ${ }^{123}$

The stability of materials is not only a relevant topic for batteries, as can be seen in some of the works reviewed before, but for several fields of science and technology. Ulvestad et al. ${ }^{89}$ studied the dissolution and redeposition of $\mathrm{Ag}^{+}$from $\mathrm{Ag}$ NPs with size ranging from 300 to $500 \mathrm{~nm}$ in electrochemical ambient. BCDI allowed monitoring in situ changes in the volume and in the strain due to the dissolution/redeposition process (Figure 4) with 20-30 nm resolution. They showed that dissolution is faster in more strained regions.

Another important topic, which has been proven to be important for electrochemistry is the dealloying of nanomaterials. ${ }^{170,171}$ For example, electrochemically dealloyed NPs are among the most active catalyst for several relevant reactions such as oxygen reduction ${ }^{172}$ and dealloyed Au NPs are used as an important anode substrate for Li-ion batteries ${ }^{173}$ and as a constituent material in supercapacitors. ${ }^{174}$

Cha et al. ${ }^{152}$ studied the dealloying process of $\mathrm{Au}-\mathrm{Ag}$ NPs alloys. They exposed the NP to $\mathrm{HNO}_{3}$ inducing the $\mathrm{Ag}$ leaching. BCDI allowed following the process through several parameters. The BCDI images permit one to observe a marked change in the NP shape, starting with an alloy with a smooth surface and finishing with an Au-rich rough material (the data are consistent with ex situ SEM images). The decrease in the intensity of the Bragg peak in several regions is consistent with the generation of pores. Besides, the shift of the Bragg peak permitted one to follow a decrease in the average lattice constant, which is consistent with XRD results (which permit one to track the same parameter but averaged through all of the sample). In agreement with the work of Ulvestad et al., ${ }^{89}$ the authors showed that the dissolution generates strain, which could explain the improved and unexpected results obtained in electrocatalysis with dealloyed nanomaterials. ${ }^{175,176}$ ChenWiegart et al. ${ }^{151}$ studied a similar system but monitored in detail the development and distribution of different kinds of strain throughout the particle. They showed that although the 


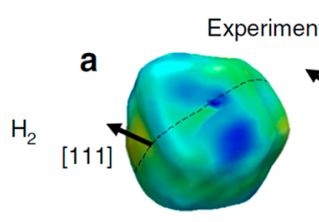

Experimental results
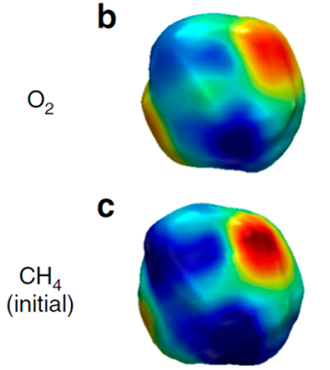

d

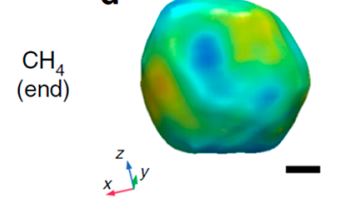

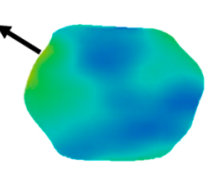
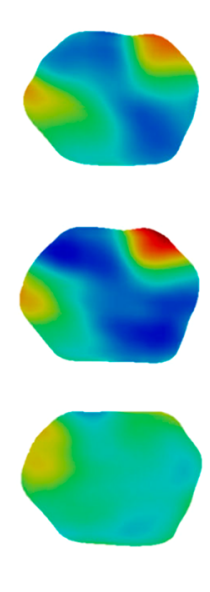

\section{f}

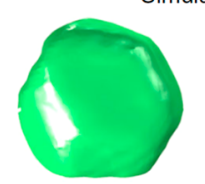

g

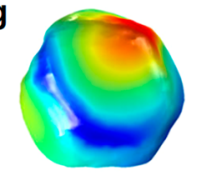

h

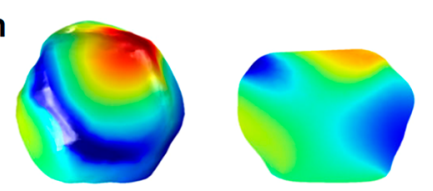

e
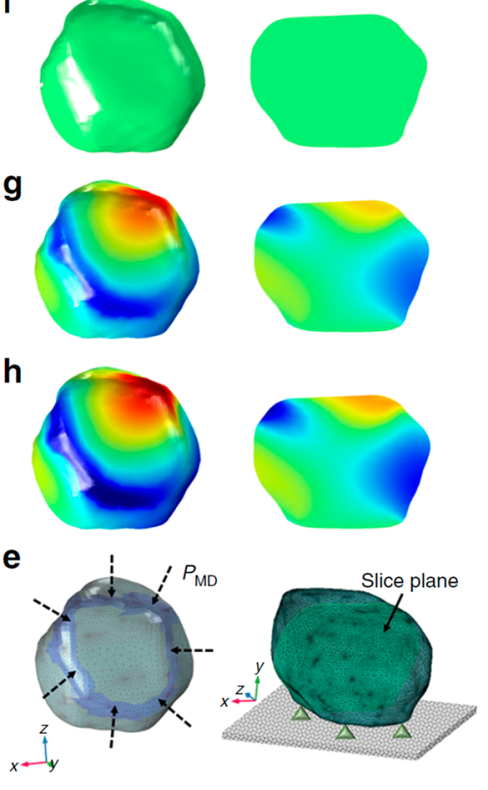

$-0.057$

0

Displacement (nm)

Figure 5. Displacement distribution obtained from BCDI and complementary computational (finite element analysis) experiments. (a-d) 3D images of a $220 \mathrm{~nm} \mathrm{Pt} \mathrm{nanocrystal} \mathrm{(left)} \mathrm{and} \mathrm{the} \mathrm{corresponding} \mathrm{sliced} \mathrm{images} \mathrm{(right).} \mathrm{The} \mathrm{lattice} \mathrm{displacement} \mathrm{field} \mathrm{at} \mathrm{(111)} \mathrm{shows} \mathrm{a}$ varying distribution of intensities when the particle is exposed to different atmospheres. Red (positive sign) indicates a contraction along the [111] direction and blue (negative sign) an expansion. These 3D images show that adsorption of oxygen and methane oxidation generate a contraction at the corners and edges. The cross-sections show the propagation of the distortion into the interior of the NPs. After the oxidation of methane, the distortions are released, both at the surface and in the particle bulk. (e) Images on the left show finite element mesh as well as the boundary conditions applied. Forces computed from reactive molecular dynamics (RMD) per unit area are applied to the region shaded in blue. Image on the right shows the Dirichlet constraint of zero displacement, included in the finite element analysis (FEA). The slice plane used for panels $\mathrm{f}-\mathrm{h}$ is also shown. $(\mathrm{f}-\mathrm{h}$ ) FEA predictions for the Pt nanocrystal response to adsorption induced external force obtained from RMD compared to experimental results in panels a-c. Crystal and slice planes are colored by the [111] projected displacement. Scale bar corresponds to $50 \mathrm{~nm}$. Reprinted with permission from ref 48. Copyright 2018 Springer Nature.

nanopores start to develop at the surface, after $10 \mathrm{~s}$, the strain is maximized at the bulk of the particle and near the substrate.

To the best of our knowledge, there are no more contributions including BCDI in electrochemical conditions, except for the work from Björling et al. that will be described in another section. However, we highlight some contributions that do not belong to the field of electrochemistry. Several articles about heterogeneous catalysis have applied BCDI to get a deeper understanding about the underlying mechanism involved in these processes. We will review some of them as we visualize a relatively straightforward transition to the electrochemical ambient and because they were performed using materials and systems of enormous interest for the field of electrocatalysis.

A series of articles have studied reactions and/or adsorption of different molecules on noble metal NPs, which are the most used materials in the field of electrocatalysis. Kim et al. ${ }^{48}$ monitored atom displacement on $\sim 200 \mathrm{~nm}$ Pt nanocrystals during the heterogeneous oxidation of methane with $14 \mathrm{~nm}$ resolution (Figure 5). They observed a much higher strain in the nanocrystal edges caused by the adsorption of oxygen and methane during oxidation. RMD simulation permitted an explanation of the changes in the measured displacement field in terms of the interactions between the molecules and the $\mathrm{Pt}$ atoms. As shown in the examples above, the variation of the displacement field and the corresponding strain can have several origins. Thus, computational experiments are valuable to correlate these parameters with interactions between the atoms and molecules of the system. In another article of the same group, they worked with the same systems but studied the evolution of the defects and dislocations after the catalytic cycle of methane oxidation. ${ }^{118}$ They observed that the dynamics of the defects and dislocations originated from strained parts of the particle. Besides, they observed that the strain propagates to the bulk of the particle during the reaction and that the crystal returns to the same condition after reaction completion. The authors postulated that the deformations in the crystal could be the origin of the degradation of the catalysts after several reaction cycles.

Finally, the same authors studied the decomposition of hydrogen peroxide on single Pt NPs $(150-500 \mathrm{~nm})$ in aqueous media, i.e., in a similar ambient to that often used in electrocatalysis; however, they did not study the effect of the electrochemical potential. ${ }^{105}$ They observed a strain distribution from the NP bulk until the surface at the (111) Bragg reflection. On the other hand, minor changes were observed on the (100) Bragg reflection. DFT experiments permitted understanding of these findings in terms of the interaction between hydroxyl groups and the Pt atoms at the NP surface in the (111) and (100) facets.

Stierle et al. also made important contributions regarding the effects of adsorption on strain and the overall BCDI response. They used BCDI to study the effect of atmospheres of Ar and $\mathrm{Ar} / \mathrm{CO}$ on a $160 \mathrm{~nm} \mathrm{Pt} \mathrm{NP}$ supported onto $\mathrm{SrTiO}_{3}(001) .^{119}$ 

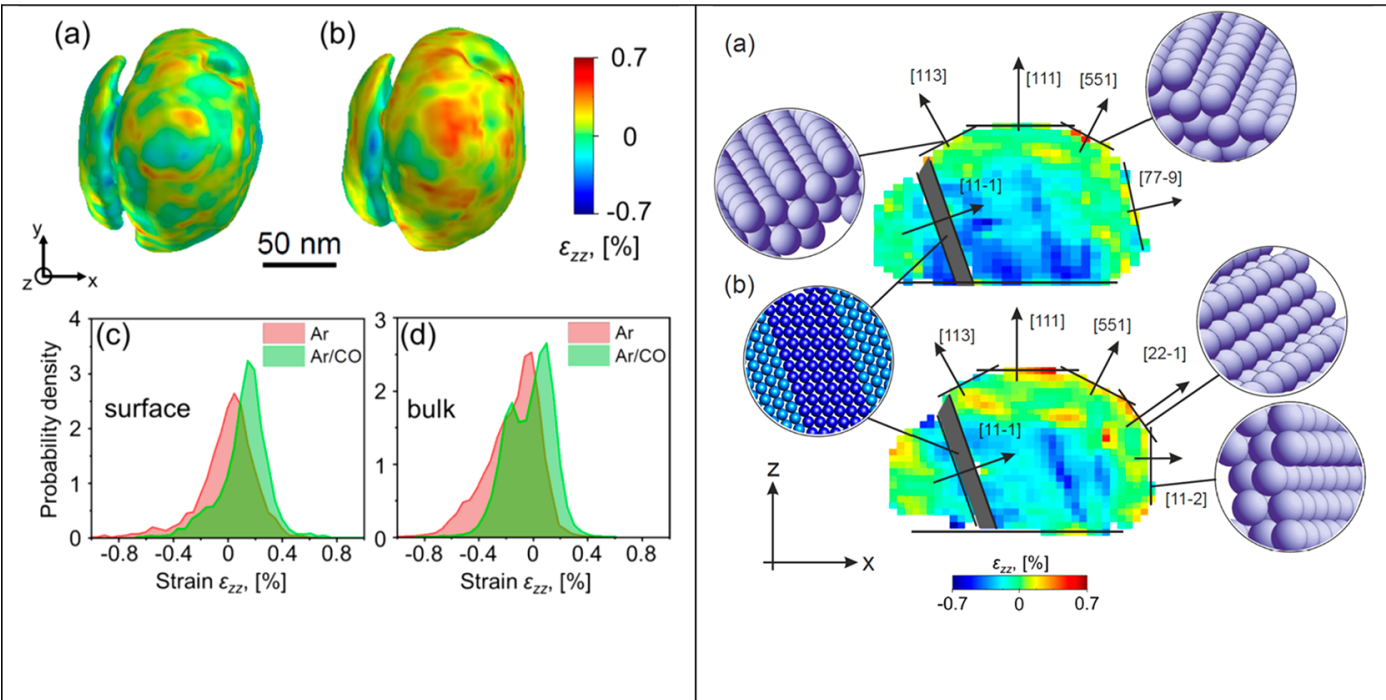

Figure 6. (Left) Reconstruction of the Pt NP (a) under Ar flow and (b) under mixed Ar/CO flow. The color map represents the strain field component $\left(\varepsilon_{z z}\right)$ intensity at the NP surface. (c) Probability density of the strain field in the NP near surface region and (d) in the bulk. The average near the surface and bulk strain field changes from $-0.8 \%$ from compressive strain to $+0.4 \%$ of tensile strain. Besides, the distribution of the strain in the NP surface and bulk change when switching from pure Ar to Ar/CO flow, respectively. (Right) Strain field in a slice crossing the center of the NP in an $\mathrm{Ar}(\mathrm{a})$ and $\mathrm{Ar} / \mathrm{CO}$ (b) atmosphere. The [111] direction ( $z$-axes) and other vicinal planes are highlighted, together with each corresponding atom arrangement in a perfect crystal. The region in gray shows the fault region (see in the image to the left that the particle seems to be formed by two particles). This data treatment permits one to relate strain to different facets, which is extremely important information in catalysis. Besides, it permits one to differentiate the effect of the atmosphere in the terrace and uncoordinated sites (kinks, steps, and so on). Reprinted with permission from ref 119. Copyright 2017 American Chemical Society.

Interestingly, they got the SEM, AFM, and BCDI images of the same particle. They observed a compressive strain in the bulk and a slight expansion at the surface of the particle in the presence of Ar. On the other hand, CO induced changes in the shape of the NP and an expansion of the lattice, even reaching the NP bulk (Figure 6, left). Besides, they showed how the structure is affected at the surface in the different facets of the crystal (Figure 6, right) which is a key result to understand the behavior of the materials in the field of (electro)catalysis. In another contribution of the group, ${ }^{113}$ they studied the $\mathrm{CO}$ oxidation on cuboctahedral PtRh alloy NPs supported on $\mathrm{MgAl}_{2} \mathrm{O}_{4}$ (001). They measured the reflections around the reciprocal lattice vectors $\mathbf{G}_{111}$ and $\mathbf{G}_{100}$ and were able to follow the formation of bulk and surficial oxides in the facets (111) and (100). Interestingly, the authors linked the formation of an $\mathrm{O}-\mathrm{Rh}-\mathrm{O}$ trilayer surface oxide on the (100) facets with an increase in the $\mathrm{CO}_{2}$ production. It is worth noticing that the authors did not pay attention to the NP strain, which has been the most studied parameter (apart from the imaging) in BCDI. In a final example of this group, ${ }^{114}$ they studied again $\mathrm{PtRh}$ NPs, with around $200 \mathrm{~nm}$ with $13 \mathrm{~nm}$ spatial resolution, relating the displacement field to compositional distributions. They found that when the particle is exposed to $\mathrm{He}$, it has only a thin layer of native oxide on its surface. Exposure to $\mathrm{O}_{2}$ generates the growth of a $\mathrm{Rh}$ oxide layer and the segregation of $\mathrm{Rh}$ to the NP surface. The subsequently exposure to $\mathrm{H}_{2}$ reduces the oxide layer, generating a particle with a $\mathrm{Rh}$-rich surface.

Shpyrko et al. ${ }^{56}$ studied the decomposition of ascorbic acid on an Au NPs with sizes around $200 \mathrm{~nm}$ and spatial resolution of $17 \mathrm{~nm}$. They measured induced local strain in several parts of the NP and, through RMD simulations, they concluded that the strain was caused by the chemisorption of hydroxyl ions in those regions, which is in line with the previous discussions for the oxidation of methane and CO on Pt NPs. In the same vein, a group from the Brazilian Synchrotron Light Laboratory published two works about the oxidation of $\mathrm{CO}$ on $\mathrm{Au}$ NPs. ${ }^{116,120}$ Suzana et al. ${ }^{116}$ imaged Au NPs of $120 \mathrm{~nm}$ supported on $\mathrm{TiO}_{2}$ with $12 \mathrm{~nm}$ resolution, showing the development of strain during $\mathrm{CO}$ oxidation at high temperatures. The results show that surface reconstruction occurs during the oxidation, leading to the formation of defects and distorted lattice which serves as preferential active sites. Passos et al. ${ }^{120}$ went a step forward working with shape-controlled $\mathrm{Au}$ NPs of $60 \mathrm{~nm}$, tracking the strain in the NP bulk and surface during the catalytic oxidation. They studied the oxidation of $\mathrm{CO}$ on these NP during a heating and cooling cycle, which is well-known to present hysteresis. They observed that the development of the strain is anisotropic; i.e., the same kind of facet is affected in different ways in both cycles. Besides, for a given region of the particle, at a given temperature, the observed strain is different in the heating and cooling cycles, following the hysteresis observed in a conventional experiment of $\mathrm{CO}$ oxidation.

Ulvestad et al..$^{59,85,86}$ studied the absorption of $\mathrm{H}_{2}$ in Pd NPs. BCDI permitted visualization of atoms' displacements, strain, and phase transition during the insertion of $\mathrm{H}$ in different regions of the Pd NP. The electrochemical storage of $\mathrm{H}_{2}$ is an important topic in electrochemistry; ${ }^{177}$ therefore, studies similar to those described in these works could be carried out under electrochemical conditions, with the electrochemical potential as the driving force for the $\mathrm{H}$ insertion in the solid matrix and water being the source of $\mathrm{H}$ atoms.

The several works revised here in the field of batteries showed that BCDI can be used in electrochemical ambient. The works in the field of catalysis showed that BCDI is an excellent tool to study the effect of the adsorption of molecules on the structure of the catalysts. These results show that 
ground has been prepared to go a step further and study systems similar to those revised before for heterogeneous catalysis in electrochemical ambient to then move to unexplored materials and even to (photo)electrochemical systems.

\section{ROLE OF SURFACE STRAIN IN ELECTROCATALYSIS}

Electrocatalysis is a heterogeneous process that takes place at the surface of an electrocatalyst. Consequently, according to the Sabatier principle, the properties of this surface, including its atomic composition, morphology, and structure, will determine the adsorption strength of the reactants, products, and intermediates, thus controlling the resulting electrocatalytic reactivity (activity, selectivity, and stability) of the electrocatalysts. ${ }^{178}$ Briefly, as described by the Sabatier principle, for a given electrocatalytic reaction, the adsorption strengths should be neither too strong nor too weak to display an optimized behavior. Thus, these binding strengths between the electrocatalytic surface and the adsorbates will govern the reaction rate. In fact, several times the binding energy of intermediates can be also considered as the reaction descriptor and plotting the measured electrocatalytic activities as a function of the binding strength of one of the intermediates will result in a volcano curve from which the optimal binding energy can be visualized. Under these conditions, tuning the adsorption strength of the electrocatalysts represents one of the most interesting approaches to developing enhanced electrocatalytic materials. ${ }^{178}$ Two main approaches have generally been used to modify this binding strength of the intermediate species, (i) modifying the electronic structure of the electrocatalysts and (ii) altering the surface geometry of the surfaces. ${ }^{179,180}$

For instance, at the nanoscale, the use of alloyed NPs and shape-controlled NPs is a well-established methodology to properly modify the electronic properties and surface structure of the electrocatalytic nanomaterials, respectively. ${ }^{181-184}$ In this respect, it is well-established that the adsorption strength is correlated with the position of the d-band center. According to this d-band model, ${ }^{185}$ the position of the d-band center determines both adsorption energies and activation energy barriers. Besides, controlling surface strain is also an interesting strategy to tune the adsorptive properties of a material and, consequently, its electrocatalytic properties. ${ }^{186-190}$

DFT calculations on model catalysts have clearly demonstrated how strain alters the d-band center of catalytic metals, thus enhancing the electrocatalytic activity. ${ }^{185,191,192}$ In this regard, overlaying a catalytic layer on a substrate has been the most convenient methodology to modify surface strain. For instance, developing core-shell architectures is the most common way to induce surface strain. In these core-shell systems, the lattice mismatch between the core and the shell is the origin of the lattice strain on the surface. Several approaches have been employed to produce these core-shell architectures, such as epitaxial growth, surface dealloying, galvanic replacement, and surface segregation, among others. $^{187}$

Interestingly, the development of shape-controlled nanomaterials, that is, nanomaterials that display a well-defined and preferential surface structure, also represent a suitable way to control the surface strain as a consequence of the presence of surface atoms with different coordination numbers, including atoms at facet, edge, and corner sites. ${ }^{193}$
In terms of the d-band center model, compressive strain downshifts the $\mathrm{d}$-band center, resulting in weaker binding, whereas tensile lattice strain upshifts the d-band center, leading to stronger binding with adsorbates. ${ }^{194}$

It is also worth noting the concept of microstrain, or localized lattice strain, which is a different type of strain associated with multiple structural defects such as dislocation, grain boundaries, and multitwinning. The microstrain modifies the surface electronic structure and/or atomic arrangements being able to enhance the electrocatalytic activity and stability. ${ }^{195,196}$

Despite surface strain being well-recognized to significantly contribute to the development of enhanced electrocatalytic systems, an in-depth understanding of the effects of surface strain requires the use of advanced characterization techniques able to visualize and study surface strain under in operando electrochemical conditions in nanomaterials. In this respect, XRD has been the classical approach to study lattice strain. ${ }^{197,198}$

As described above, lattice strain is visualized by the positive or negative shift of the Bragg peak position due to lattice contraction or expansion, respectively. However, in the case of microstrain, this does not produce a shift of the peak position but a peak broadening without a shift of the peak position because of the multiple defects-induced structures. Other imaging modalities can be used to provide complementary information. For instance, aberration-corrected high resolution transmission electron microscopy (HRTEM) also including image simulation has also been employed to observe surface strain. ${ }^{199,200}$

Similarly, very promising findings have been reported by using atomic electron tomography. ${ }^{201-203}$ For instance, electron tomography was used to map the high-resolution 3D strain field on gold nanorods. ${ }^{201}$ Multimodal techniques (including the use of BCDI) to understand the role of surface and bulk strain fields are crucial to design next-generation electrocatalysts.

\section{PERSPECTIVES AND CHALLENGES}

The advent of the so-called fourth-generation light sources creates great opportunities for the development of these techniques as the beamlines of these synchrotrons permit one to perform measurements with excellent time and spatial resolution. The MAX IV synchrotron in Lund, Sweden, is one of these facilities. This class of accelerator accomplishes a diffraction-limited stored electron beam, which in turn provides low emittance $\mathrm{X}$-rays and thereby enables exceptional coherent flux density delivered to the experiment. ${ }^{20}$ At the NanoMAX beamline, this coherent light is focused into a spot approximately $100 \times 100 \mathrm{~nm}^{2}$, in theory allowing BCDI studies of NPs in the range well-below $100 \mathrm{~nm}$. However, imaging experiments at the lowest size range are limited by the relevant intensity recorded on the detector, which depends on the scattering power and NP volume. Performing simulations of the diffracted intensities is a good starting point to evaluate the constraints and the system to be studied. Overall, at a nanofocus beamline, BCDI is a great nondestructive tool for imaging low dimensional systems, also contributing to the understanding of the impact of the strain and defects in an electrocatalyst. ${ }^{204,205}$

Some of us published proof-of-principle experiments where $60 \mathrm{~nm} \mathrm{Au}$ particles were imaged under potentiostatic control. ${ }^{12}$ The NanoMAX beamline features an integrated electro- 
chemical cell, where NP suspensions can be deposited and subjected to BCDI. In this study, the potential was held in the double-layer potential region of the gold/electrolyte interface, where no specific adsorption or faradaic process occurs. The experiment produced highly resolved $2 \mathrm{D}$ projection images of several single particles (Figure 7) and showed by extrapolation

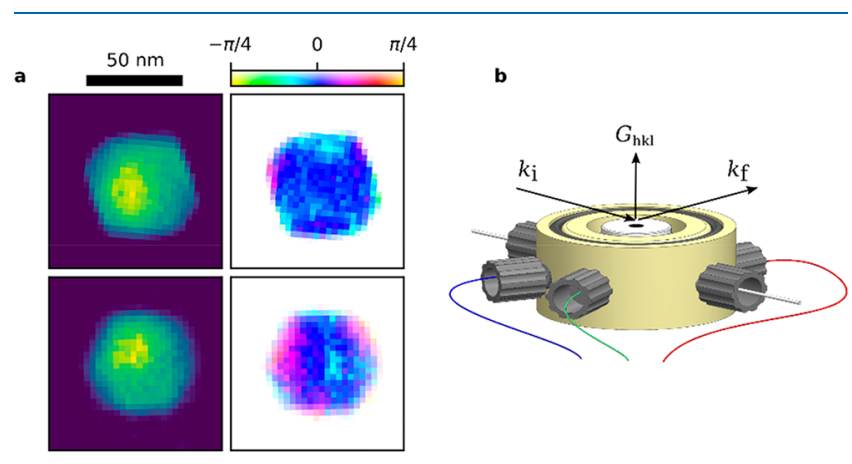

Figure 7. Summary of early in situ BCDI at the NanoMAX beamline. $^{12}$ (a) Two single-particle images in amplitude and phase. In these experiments, two-dimensional projections were reconstructed. (b) Electrochemical cell integrated at the beamline. Image courtesy of Dr. Alexander Björling.

that the focused beam at NanoMAX, which delivers around 2 $\times 10^{10}$ photons/s across a $100 \times 100 \mathrm{~nm}^{2}$ spot at $10 \mathrm{keV}$, is more than capable of imaging these particles in three dimensions in a matter of seconds. The limiting factor, however, was stability. The intense beam causes particles to move, a phenomenon previously described in a BCDI context. ${ }^{206}$ To gather static diffraction patterns, the beam intensity had to be reduced by filtering. While other sample systems will probably prove more resistant to the effects of the beam, sample movements must clearly be accepted and accounted for in both the data acquisition schemes and the data analysis steps. To solve this problem, some work has already been reported in this field. ${ }^{207,24}$

The nanoprobe beamline (Carnaúba) ${ }^{21}$ at the SIRIUS facility, the Brazilian Synchrotron Light Source, was designed to operate from 2.05 to $15 \mathrm{keV}$, delivering a precisely focused full coherent beam $\left(10^{12}\right.$ photons/s), giving a focus of about $120 \times 120 \mathrm{~nm}^{2}$ at $8 \mathrm{keV}$. Accordingly, the diffraction experiments require a huge level of stability through the beamline to take full advantage of its potential. It is expected that the high flux of photons combined with the high efficiency of the X-ray beam focusing optics and the nanometric precision of motion in the different stages of the end-station push the final resolution to a few nanometers. Additionally, a very fast Medipix based detector ${ }^{208}$ was specially developed to operate at high acquisition rates $(2 \mathrm{kHz})$ with high throughput, which means that we will be able to obtain a large number of low noise images per second. Overall, for comparison, in fourth-generation synchrotrons, due to the large number of photons available, it is expected to carry out a BCDI experiment in a few seconds (minutes to tens of minutes for the third generation) with spatial resolution better than $10 \mathrm{~nm}$.

The Carnaúba instrumentation and the in situ experiments are being carefully planned, attending all the constraints to reach high resolution images in short acquisition times, aiming to take full advantage of the beamline capabilities. Some of us are developing the instrumentation for multitechnique spectroelectrochemical experiments, with special emphasis on in situ BCDI. Thus, in a big picture the Carnaúba beamline will be able to furnish all of the information already described for the research articles reviewed here, but with an improved spatial and temporal resolution.

Finally, the advent of big data analytics and exponential increase in leadership class computing facilities has brought to the forefront powerful machine learning and AI techniques, which can now be deployed to further improve upon the spatiotemporal resolution limits for coherent X-ray imaging techniques. These machine learning techniques, specifically deep learning based approaches and computer vision, are being researched to solve the inverse problem of information extraction. ${ }^{49,209}$ Typical phase retrieval algorithms are iterative in nature and, hence, are time-consuming and computationally expensive, making real-time imaging a challenge. Additionally, iterative phase retrieval algorithms tend to struggle with convergence to the correct solution, especially in the presence of strong phase structures. ML approaches such as deep convolutional neural networks (DNNs) provide us the possibility to circumvent the tedious phase reconstruction problem associated with BCDI imaging and can potentially allow for real-time image reconstructions and feature/event detection. Preliminary work by Cherukara and co-workers seems to show promise in the use of deep neural networks for accelerated reconstructions and improved resolutions ${ }^{49,209}-$ such efforts will be crucial to image and study the role of defects including point defects in influencing the electrocatalyst performance under operando conditions. We anticipate an increasing role of $\mathrm{AI}$ and $\mathrm{ML}$ in providing users a more comprehensive understanding of the catalyst response at high spatial resolution, across multiple length scales and under realworld conditions.

\section{CONCLUSION AND OUTLOOK}

In this review, we have highlighted the potential of BCDI for electrochemical applications. We believe that the recent and future development in the technique can help to unravel many problems across several fields of science and technology involving nanomaterials, and electrochemistry is no exception. Even though the obtention of images is the aspect that more easily calls the attention of the researchers when the technique is introduced, the great resolution to monitor the lattice displacement field can be a key point to understand many relevant processes. At this point, it is important to stress that BCDI is very sensitive to changes in this parameter but does not directly inform whether it is due to strain, to dislocation, or to any other defect generated in the crystal lattice. Thus, to get a big picture of the phenomena occurring at the solution/ electrode interface, it is important to combine complementary in situ techniques and computational experiments.

Chemical adsorption of reaction intermediates, dissolution, and deposition of atoms, etc., occurring at the monolayer or even sub-monolayer level, have been studied for decades in the field of electrochemistry. These events are far beyond the resolution of the imaging capacities of the technique. However, these processes can be indirectly visualized by following changes in the lattice displacement. Thus, the combination of spectroscopic techniques and BCDI could render extremely valuable information in the field. For instance, spectroscopy can give information about the nature of the adsorbate and BCDI inform where it adsorbs (which facet, edge, and so on), and which is the dependence with the electrochemical potential. 
Even though, at least to the best of our knowledge, any article about photocatalysis or photoelectrocatalysis using BCDI has been published, the results shown before suggest that it is possible to perform in situ BCDI experiments to study the effect of the light in an electrochemical process. Thus, the only difference with conventional experiments is that the nanomaterials will be semiconductors and we will place a solar simulator or a LED in front of the electrode.

In conclusion, we point out that BCDI is an evolving technique and has taken several strides toward enabling 3D imaging of nanoscale structures under operando conditions. Nonetheless, there are several limitations that are intrinsic to both beamlines and the system. Thus, to follow the electrochemical process/chemical reactions and its effects on the crystalline structure at nanoscale by an imaging technique, it is a huge challenge when the phenomena occur very fast (compared to the sample rocking); then there is a compromise between the experiment time and stability to achieve a good resolution in $3 \mathrm{D}$ images. It means that to perform a high stable measurement, which is partially filled by the precise mechanical nanopositioners as aforementioned, the acquisition rate in some cases decreases, increasing the experiment time. Moreover, the thermal stability of the station, the particle stability in front of a highly intense beam, and the vibrational behavior of the experimental station are also sources of instability, drastically affecting the final resolution. As with most developing techniques, it is strongly advised to perform control experiments, i.e., to get BCDI results with a system under conditions previously studied with other techniques as a benchmark.

\section{ASSOCIATED CONTENT}

\section{SI Supporting Information}

The Supporting Information is available free of charge at https://pubs.acs.org/doi/10.1021/acsnano.1c01080.

Table listing all the papers about BCDI, the nature and size of the materials studied, the main results, and the synchrotrons where the measurements were performed (PDF)

\section{AUTHOR INFORMATION}

\section{Corresponding Author}

Pablo S. Fernández - Chemistry Institute, State University of Campinas, 13083-970 Campinas, São Paulo, Brazil; Center for Innovation on New Energies, University of Campinas, 13083-841 Campinas, São Paulo, Brazil; @orcid.org/ 0000-0002-5068-0556; Email: pablosf@unicamp.br

\section{Authors}

Rafael A. Vicente - Chemistry Institute, State University of Campinas, 13083-970 Campinas, São Paulo, Brazil; Center for Innovation on New Energies, University of Campinas, 13083-841 Campinas, São Paulo, Brazil

Itamar T. Neckel - Brazilian Synchrotron Light Laboratory, Brazilian Center for Research in Energy and Materials, 13083-970 Campinas, São Paulo, Brazil

Subramanian K. R. S. Sankaranarayanan - Department of Mechanical and Industrial Engineering, University of Illinois, Chicago, Illinois 60607, United States; Center for Nanoscale Materials, Argonne National Laboratory, Argonne, Illinois 60439, United States; ㅇo이.org/0000-0002-9708-396X
José Solla-Gullon - Institute of Electrochemistry, University of Alicante, E-03080 Alicante, Spain; 이이이.org/0000-00029570-8110

Complete contact information is available at:

https://pubs.acs.org/10.1021/acsnano.1c01080

\section{Author Contributions}

All of the authors discussed all of the content of the manuscript. R.A.V. and I.T.N. contributed equally to this work. I.T.N. was mainly responsible for section Fundamental Aspects of BCDI. S.K.R.S.S. was mainly responsible for the section about computational chemistry. J.S.-G. was mainly responsible for section Role of Surface Strain in Electrocatalysis. R.A.V. and P.S.F. were mainly responsible for section BCDI Applied to Electrochemistry and Heterogeneous Catalysis and the Supporting Information. P.S.F. was mainly responsible for the Introduction, Perspectives and Challenges, and Conclusions and Outlook and for the organization of the work.

Notes

The authors declare no competing financial interest.

\section{ACKNOWLEDGMENTS}

Financial support from Brazilian agencies: P.S.F. thanks FAPESP (Grants 2017/11986-5, 2018/20952-0, and 2019/ 13888-6 (RAV fellowship)), CNPq (Grant136436/2019-6 (RAV fellowship)), Shell, and the strategic importance of the support given by ANP (Brazil's National Oil, Natural Gas and Biofuels Agency) through the R\&D levy regulation. Use of the Center for Nanoscale Materials, an Office of Science user facility, was supported by the U.S. Department of Energy (DOE), Office of Science, Office of Basic Energy Sciences, under Contract No. DE-AC02-06CH11357. This material is based upon work supported by the U.S. Department of Energy, Office of Science, Office of Basic Energy Sciences Data, Artificial Intelligence and Machine Learning at DOE Scientific User Facilities program under Award No. 34532. We also thank the Carnaúba group, in particular Francisco M. C. da Silva for providing simulations on coherent diffraction used in Figure ${ }^{1}$. Finally, we kindly thank Dr. Alexander Björling for his help in the discussion about the fundamental aspects of BCDI, for giving us some technical information on the NanoMAX beamline, and for use of Figures 2 and 7.

\section{VOCABULARY}

Electrocatalysis, It is a kind of heterogeneous catalysis that occurs at the interface electrode-solution and that results in an increase of the rate of an electrochemical reaction; In Situ Experiments, In the context of (electro)catalysis, these are experiments performed in real time, in experimental conditions relevant for the problem but not necessarily equal to those in an (electro)chemical reactor; Coherent Diffraction Imaging, It is a technique that explores the coherence of an X-ray beam (micro and nano) generated by a synchrotron radiation machine, and phase retrieval algorithms. When the technique is applied to crystalline solids, at specific Bragg reflection, the nanobeam is sensitive to displacements in the order of the picometer; Strain, In (electro)catalysis, strain is a dimensionless measure of relative deformations that deeply impact (electro)chemical reactions. It is also obtained at the nanoscale, at atomic or crystalline structure level, taking advantage of sensitive techniques such as coherent nano- 
diffraction imaging; Multiscale Models, Computational models that span a wide range of spatial and temporal scales from electronic structure calculations ( $\mathrm{nm}, \mathrm{ps}$ ) to molecular dynamics $(\mathrm{m}, \mathrm{ns})$ to finite element models $(\mathrm{m}, \mathrm{s})$. These models provide information on the structural evolution and dynamics of the material system being studied; Machine Learning, Computer algorithms that allow for circumventing the phase retrieval for reconstruction, extracting enhanced information by combining simulations with imaging, and realtime dynamical information.

\section{REFERENCES}

(1) Acres, G. J. K.; Hards, G. A.; Dell, R. M.; Huggins, R. A.; Parsons, R.; Steele, B. C. H.; Vincent, A. C. Electrocatalysts for Fuel Cells. Philos. Trans. R. Soc., A 1996, 354 (1712), 1671-1680.

(2) Debe, M. K. Electrocatalyst Approaches and Challenges for Automotive Fuel Cells. Nature 2012, 486 (7401), 43-51.

(3) Yuan, X.-Z.; Wang, H. In PEM Fuel Cell Electrocatalysts and Catalyst Layers: Fundamentals and Applications; Zhang, J., Ed.; Springer: London, 2008. DOI: 10.1007/978-1-84800-936-3 1.

(4) Seh, Z. W.; Kibsgaard, J.; Dickens, C. F.; Chorkend̄orff, I.; Nørskov, J. K.; Jaramillo, T. F. Combining Theory and Experiment in Electrocatalysis: Insights into Materials Design. Science 2017, 355 (6321), eaad4998.

(5) Turner, J. A. Sustainable Hydrogen Production. Science (Washington, DC, U. S.) 2004, 305 (5686), 972-974.

(6) Grigoriev, S. A.; Porembsky, V. I.; Fateev, V. N. Pure Hydrogen Production by PEM Electrolysis for Hydrogen Energy. Int. J. Hydrogen Energy 2006, 31 (2), 171-175.

(7) Ni, M.; Leung, M. K. H.; Leung, D. Y. C. Technological Development of Hydrogen Production by Solid Oxide Electrolyzer Cell (SOEC). Int. J. Hydrogen Energy 2008, 33 (9), 2337-2354.

(8) Fan, L.; Xia, C.; Yang, F.; Wang, J.; Wang, H.; Lu, Y. Strategies in Catalysts and Electrolyzer Design for Electrochemical $\mathrm{CO}_{2}$ Reduction toward $\mathrm{C}_{2+}$ Products. Sci. Adv. 2020, 6 (8), eaay3111.

(9) Koper, M. T. M. Structure Sensitivity and Nanoscale Effects in Electrocatalysis. Nanoscale 2011, 3 (5), 2054-2073.

(10) Grassian, V. H. When Size Really Matters: Size-Dependent Properties and Surface Chemistry of Metal and Metal Oxide Nanoparticles in Gas and Liquid Phase Environments. J. Phys. Chem. C 2008, 112 (47), 18303-18313.

(11) Westsson, E.; Picken, S.; Koper, G. The Effect of Lattice Strain on Catalytic Activity. Chem. Commun. 2019, 55 (9), 1338-1341.

(12) Björling, A.; Carbone, D.; Sarabia, F. J.; Hammarberg, S.; Feliu, J. M.; Solla-Gullón, J. Coherent Bragg Imaging of $60 \mathrm{~nm} \mathrm{Au}$ Nanoparticles under Electrochemical Control at the NanoMAX Beamline. J. Synchrotron Radiat. 2019, 26, 1830-1834.

(13) NanoMAX, MAX IV Laboratory, Lund, Sweden; https://www. maxiv.lu.se/accelerators-beamlines/beamlines/nanomax/ (acessed 2021-03-15).

(14) Carnaúba, Brazilian Synchrotorn Light Laboratory (LNLS), Sao Paulo, Brazil; https://www.lnls.cnpem.br/grupos/carnauba-en/ (acessed 2021-03-15).

(15) Gasbarro, A.; Bazarov, I. Reduced Forms of the Wigner Distribution Function for the Numerical Analysis of Rotationally Symmetric Synchrotron Radiation. J. Synchrotron Radiat. 2014, 21 (2), 289-299.

(16) Bilderback, D. H.; Elleaume, P.; Weckert, E. Review of Third and Next Generation Synchrotron Light Sources. J. Phys. B: At., Mol. Opt. Phys. 2005, 38 (9), S773.

(17) Ghasem, H.; Bartolini, R.; Einfeld, D.; Ghasem, H.; Bartolini, R.; Kingdom, U. A 4th Generation Light Source for South-East Europe. 9th International Particle Accelerator Conference (IPAC2018), Vancouver, BC, Canada; JACoW, 2018; DOI: 10.18429/JACoWIPAC2018-THPMF020

(18) Pacchioni, G. An Upgrade to a Bright Future. Nat. Rev. Phys. 2019, 1 (2), 100-101.
(19) Westfahl, H.; Lordano Luiz, S. A.; Meyer, B. C.; Meneau, F. The Coherent Radiation Fraction of Low-Emittance Synchrotrons. J. Synchrotron Radiat. 2017, 24 (3), 566-575.

(20) Björling, A.; Kalbfleisch, S.; Kahnt, M.; Sala, S.; Parfeniukas, K.; Vogt, U.; Carbone, D.; Johansson, U. Ptychographic Characterization of a Coherent Nanofocused X-Ray Beam. Opt. Opt. Express 2020, 28 (4), 5069.

(21) Tolentino, H. C. N.; Soares, M. M.; Perez, C. A.; Vicentin, F. C.; Abdala, D. B.; Galante, D.; Teixeira, V. D. C.; De Araujo, D. H. C.; Westfahl, H. CARNAUBA: The Coherent X-Ray Nanoprobe Beamline for the Brazilian Synchrotron SIRIUS/LNLS. J. Phys.: Conf. Ser. 2017, 849 (1), 012057.

(22) Dietze, S. H.; Shpyrko, O. G. Coherent Diffractive Imaging: Towards Achieving Atomic Resolution. J. Synchrotron Radiat. 2015, $22,1498-1508$.

(23) Howells, M. R.; Beetz, T.; Chapman, H. N.; Cui, C.; Holton, J. M.; Jacobsen, C. J.; Kirz, J.; Lima, E.; Marchesini, S.; Miao, H.; Sayre, D.; Shapiro, D. A.; Spence, J. C. H.; Starodub, D. An Assessment of the Resolution Limitation Due to Radiation-Damage in X-Ray Diffraction Microscopy. J. Electron Spectrosc. Relat. Phenom. 2009, $170(1-3), 4-12$.

(24) Björling, A.; Marçal, L. A. B.; Solla-Gullón, J.; Wallentin, J.; Carbone, D.; Maia, F. R. N. C. Three-Dimensional Coherent Bragg Imaging of Rotating Nanoparticles. Phys. Rev. Lett. 2020, 125 (24), 246101.

(25) Li, N.; Dupraz, M.; Wu, L.; Leake, S. J.; Resta, A.; Carnis, J.; Labat, S.; Almog, E.; Rabkin, E.; Favre-Nicolin, V.; Picca, F. E.; Berenguer, F.; van de Poll, R.; Hofmann, J. P.; Vlad, A.; Thomas, O.; Garreau, Y.; Coati, A.; Richard, M. I. Continuous Scanning for Bragg Coherent X-Ray Imaging. Sci. Rep. 2020, 10 (1), 12760.

(26) Sutton, M.; Mochrie, S. G. J.; Greytak, T.; Nagler, S. E.; Berman, L. E.; Held, G. A.; Stephenson, G. B. Observation of Speckle by Diffraction with Coherent X-Rays. Nature 1991, 352, 608-610.

(27) Miao, J.; Sayre, D.; Chapman, H. N. Phase Retrieval from the Magnitude of the Fourier Transforms of Nonperiodic Objects. J. Opt. Soc. Am. A 1998, 15 (6), 1662.

(28) Fienup, J. R. Phase Retrieval Algorithms: A Comparison. Appl. Opt. 1982, 21 (15), 2758.

(29) Miao, J.; Charalambous, P.; Kirz, J.; Sayre, D. Extending the Methodology of X-Ray Crystallography to Allow Imaging of Micrometre-Sized Non-Crystalline Specimens. Nature 1999, 400 (6742), 342-344.

(30) Robinson, I. K.; Vartanyants, I. A.; Williams, G. J.; Pfeifer, M. A.; Pitney, J. A. Reconstruction of the Shapes of Gold Nanocrystals Using Coherent X-Ray Diffraction. Phys. Rev. Lett. 2001, 87 (19), 195505.

(31) Robinson, I.; Harder, R. Coherent X-Ray Diffraction Imaging of Strain at the Nanoscale. Nat. Mater. 2009, 8 (4), 291-298.

(32) Favre-Nicolin, V.; Mastropietro, F.; Eymery, J.; Camacho, D.; Niquet, Y. M.; Borg, B. M.; Messing, M. E.; Wernersson, L. E.; Algra, R. E.; Bakkers, E. P. A. M.; Metzger, T. H.; Harder, R.; Robinson, I. K. Analysis of Strain and Stacking Faults in Single Nanowires Using Bragg Coherent Diffraction Imaging. New J. Phys. 2010, 12, 035013.

(33) Van Der Veen, F.; Pfeiffer, F. Coherent X-Ray Scattering. J. Phys.: Condens. Matter 2004, 16 (28), 5003-5030.

(34) Landau, L. D.; Lifshitz, E. M.; Pitaevskii, L. P.; KOSEVICH, A. M. Theory of Elasticity, 3rd ed.; Butterworth-Heinemann, Elsevier: Oxford, U.K., 1986. DOI: 10.1016/C2009-0-25521-8.

(35) Karpov, D.; Fohtung, E. Bragg Coherent Diffractive Imaging of Strain at the Nanoscale. J. Appl. Phys. 2019, 125 (12), 121101.

(36) Miao, J.; Kirz, J.; Sayre, D. The Oversampling Phasing Method. Acta Crystallogr., Sect. D: Biol. Crystallogr. 2000, 56 (10), 1312-1315.

(37) Miao, J.; Sayre, D. On Possible Extensions of X-Ray Crystallography through Diffraction-Pattern Oversampling - Sampling the Pattern of a Finite Specimen at a Spacing Finer than the Nyquist Spacing. Acta Crystallogr., Sect. A: Found. Crystallogr. 2000, 56, 596605.

(38) Yau, A.; Cha, W.; Kanan, M. W.; Stephenson, G. B.; Ulvestad, A. Materials Science: Bragg Coherent Diffractive Imaging of Single- 
Grain Defect Dynamics in Polycrystalline Films. Science (Washington, DC, U. S.) 2017, 356 (6339), 739-742.

(39) Zhang, L.; Shi, W.; Zhang, B. A Review of Electrocatalyst Characterization by Transmission Electron Microscopy. J. Energy Chem. 2017, 26 (6), 1117-1135.

(40) Oztürk, H.; Huang, X.; Yan, H.; Robinson, I. K.; Noyan, I. C.; Chu, Y. S. Performance Evaluation of Bragg Coherent Diffraction Imaging. New J. Phys. 2017, 19 (10), 103001.

(41) Cherukara, M. J.; Pokharel, R.; O'Leary, T. S.; Baldwin, J. K.; Maxey, E.; Cha, W.; Maser, J.; Harder, R. J.; Fensin, S. J.; Sandberg, R. L. Three-Dimensional X-ray Diffraction Imaging of Dislocations in Polycrystalline Metals under Tensile Loading. Nat. Commun. 2018, 9 (1), 3776 .

(42) Cherukara, M. J.; Sasikumar, K.; Cha, W.; Narayanan, B.; Leake, S. J.; Dufresne, E. M.; Peterka, T.; McNulty, I.; Wen, H.; Sankaranarayanan, S. K. R. S.; Harder, R. J. Ultrafast ThreeDimensional X-Ray Imaging of Deformation Modes in $\mathrm{ZnO}$ Nanocrystals. Nano Lett. 2017, 17 (2), 1102-1108.

(43) Cherukara, M. J.; Sasikumar, K.; Dichiara, A.; Leake, S. J.; Cha, W.; Dufresne, E. M.; Peterka, T.; McNulty, I.; Walko, D. A.; Wen, H.; Sankaranarayanan, S. K. R. S.; Harder, R. J. Ultrafast ThreeDimensional Integrated Imaging of Strain in Core/Shell Semiconductor/Metal Nanostructures. Nano Lett. 2017, 17 (12), 76967701.

(44) Cherukara, M. J.; Schulmann, D. S.; Sasikumar, K.; Arnold, A. J.; Chan, H.; Sadasivam, S.; Cha, W.; Maser, J.; Das, S.; Sankaranarayanan, S. K. R. S.; Harder, R. J. Three-Dimensional Integrated X-Ray Diffraction Imaging of a Native Strain in Multi-

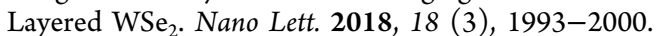

(45) Deshmukh, S.; Kamath, G.; Ramanathan, S.; Sankaranarayanan, S. K. R. S. Chloride Ions Induce Order-Disorder Transition at WaterOxide Interfaces. Phys. Rev. E 2013, 88 (6), 062119.

(46) Chan, H.; Narayanan, B.; Cherukara, M.; Loeffler, T. D.; Sternberg, M. G.; Avarca, A.; Sankaranarayanan, S. K. BLAST: Bridging Length/Timescales via Atomistic Simulation Toolkit. MRS Adv. 2021, DOI: $10.1557 /$ s43580-020-00002-z.

(47) Jeon, B.; Sankaranarayanan, S. K. R. S.; Van Duin, A. C. T.; Ramanathan, S. Reactive Molecular Dynamics Study of Chloride Ion Interaction with Copper Oxide Surfaces in Aqueous Media. ACS Appl. Mater. Interfaces 2012, 4 (3), 1225-1232.

(48) Kim, D.; Chung, M.; Carnis, J.; Kim, S.; Yun, K.; Kang, J.; Cha, W.; Cherukara, M. J.; Maxey, E.; Harder, R.; Sasikumar, K.; Sankaranarayanan, S. K. R. S.; Zozulya, A.; Sprung, M.; Riu, D.; Kim, H. Active Site Localization of Methane Oxidation on $\mathrm{Pt}$ Nanocrystals. Nat. Commun. 2018, 9 (1), 3422.

(49) Cherukara, M. J.; Nashed, Y. S. G.; Harder, R. J. Real-Time Coherent Diffraction Inversion Using Deep Generative Networks. Sci. Rep. 2018, 8 (1), 16520.

(50) Loeffler, T. D.; Patra, T. K.; Chan, H.; Sankaranarayanan, S. K. R. S. Active Learning a Coarse-Grained Neural Network Model for Bulk Water from Sparse Training Data. Mol. Syst. Des. Eng. 2020, 5 (5), 902-910.

(51) Sankaranarayanan, S. K. R. S.; Ramanathan, S. On the LowTemperature Oxidation and Ultrathin Oxide Growth on Zirconium in the Presence of Atomic Oxygen: A Modeling Study. J. Phys. Chem. C 2008, 112 (46), 17877-17882.

(52) Sankaranarayanan, S. K. R. S.; Kaxiras, E.; Ramanathan, S. Atomistic Simulation of Field Enhanced Oxidation of $\mathrm{Al}$ (100) beyond the Mott Potential. Phys. Rev. Lett. 2009, 102 (9), 095504.

(53) Sun, Y.; Zuo, X.; Sankaranarayanan, S. K. R. S.; Peng, S.; Narayanan, B.; Kamath, G. Quantitative 3D Evolution of Colloidal Nanoparticle Oxidation in Solution. Science (Washington, DC, U. S.) 2017, 356 (6335), 303-307.

(54) Zhang, Z.; Schwanz, D.; Narayanan, B.; Kotiuga, M.; Dura, J. A.; Cherukara, M.; Zhou, H.; Freeland, J. W.; Li, J.; Sutarto, R.; He, F.; Wu, C.; Zhu, J.; Sun, Y.; Ramadoss, K.; Nonnenmann, S. S.; Yu, N.; Comin, R.; Rabe, K. M.; Sankaranarayanan, S. K. R. S.; Ramanathan, S. Perovskite Nickelates as Electric-Field Sensors in Salt Water. Nature 2018, 553 (7686), 68-72.
(55) Chan, H.; Narayanan, B.; Cherukara, M. J.; Sen, F. G.; Sasikumar, K.; Gray, S. K.; Chan, M. K. Y.; Sankaranarayanan, S. K. R. S. Machine Learning Classical Interatomic Potentials for Molecular Dynamics from First-Principles Training Data. J. Phys. Chem. C 2019, 123 (12), 6941-6957.

(56) Ulvestad, A.; Sasikumar, K.; Kim, J. W.; Harder, R.; Maxey, E.; Clark, J. N.; Narayanan, B.; Deshmukh, S. A.; Ferrier, N.; Mulvaney, P.; Sankaranarayanan, S. K. R. S.; Shpyrko, O. G. In Situ 3D Imaging of Catalysis Induced Strain in Gold Nanoparticles. J. Phys. Chem. Lett. 2016, 7 (15), 3008-3013.

(57) Li, Y.; Hu, S.; Sun, X.; Stan, M. A Review: Applications of the Phase Field Method in Predicting Microstructure and Property Evolution of Irradiated Nuclear Materials. npj Comput. Mater. 2017, 3 (1), 16.

(58) Chen, L. Q. Phase-Field Models for Microstructure Evolution. Annu. Rev. Mater. Res. 2002, 32, 113-140.

(59) Ulvestad, A.; Welland, M. J.; Collins, S. S. E.; Harder, R.; Maxey, E.; Wingert, J.; Singer, A.; Hy, S.; Mulvaney, P.; Zapol, P.; Shpyrko, O. G. Avalanching Strain Dynamics during the Hydriding Phase Transformation in Individual Palladium Nanoparticles. Nat. Commun. 2015, 6, 10092.

(60) Stamatakis, M.; Vlachos, D. G. Unraveling the Complexity of Catalytic Reactions via Kinetic Monte Carlo Simulation: Current Status and Frontiers. ACS Catal. 2012, 2 (12), 2648-2663.

(61) Battaile, C. C.; Srolovitz, D. J. Kinetic Monte Carlo Simulation of Chemical Vapor Deposition. Annu. Rev. Mater. Res. 2002, 32, 297319.

(62) Cuppen, H. M.; Karssemeijer, L. J.; Lamberts, T. The Kinetic Monte Carlo Method as a Way to Solve the Master Equation for Interstellar Grain Chemistry. Chem. Rev. 2013, 113 (12), 8840-8871.

(63) Flamm, M. H.; Diamond, S. L.; Sinno, T. Lattice Kinetic Monte Carlo Simulations of Convective-Diffusive Systems. J. Chem. Phys. 2009, 130 (9), 094904.

(64) Ciccotti, G.; Frenkel, D.; McDonald, I. R. Simulation of Liquids and Solids: Molecular Dynamics and Monte Carlo Methods in Statistical Mechanics; Ciccotti, G., Daan Frenkel, I. R. M., Eds.; North-Holland: New York, 1987.

(65) Chatterjee, A.; Vlachos, D. G. An Overview of Spatial Microscopic and Accelerated Kinetic Monte Carlo Methods. J. Comput.-Aided Mater. Des. 2007, 14 (2), 253-308.

(66) Frank, H.; Althoen, S. C. Statistics: Concepts and Applications Workbook; Cambridge University Press: Cambridge, U.K., 1994.

(67) Callejas-Tovar, R.; Diaz, C. A.; De La Hoz, J. M. M.; Balbuena, P. B. Dealloying of Platinum-Based Alloy Catalysts: Kinetic Monte Carlo Simulations. Electrochim. Acta 2013, 101, 326-333.

(68) Kunz, L.; Kuhn, F. M.; Deutschmann, O. Kinetic Monte Carlo Simulations of Surface Reactions on Supported Nanoparticles: A Novel Approach and Computer Code. J. Chem. Phys. 2015, 143 (4), 044108 .

(69) García, R. E.; Chiang, Y. M.; Craig Carter, W.; Limthongkul, P.; Bishop, C. M. Microstructural Modeling and Design of Rechargeable Lithium-Ion Batteries. J. Electrochem. Soc. 2005, 152 (1), A255.

(70) Li, X.; Drews, T. O.; Rusli, E.; Xue, F.; He, Y.; Braatz, R.; Alkire, R. Effect of Additives on Shape Evolution during Electrodeposition. J. Electrochem. Soc. 2007, 154 (4), D230.

(71) Wang, C.-W.; Sastry, A. M. Mesoscale Modeling of a Li-Ion Polymer Cell. J. Electrochem. Soc. 2007, 154 (11), A1035.

(72) Doyle, M.; Fuller, T. F.; Newman, J. Modeling of Galvanostatic Charge and Discharge of the Lithium/Polymer/Insertion Cell. J. Electrochem. Soc. 1993, 140 (6), 1526-1533.

(73) Newman, J.; Balsara, N. P. Electrochemical Systems, 4th ed.; John Wiley \& Sons: Hoboken, NJ, USA, 2021.

(74) García, R. E.; Bishop, C. M.; Carter, W. C. Thermodynamically Consistent Variational Principles with Applications to Electrically and Magnetically Active Systems. Acta Mater. 2004, 52 (1), 11-21.

(75) Cherukara, M. J.; Cha, W.; Harder, R. J. Anisotropic NanoScale Resolution in 3D Bragg Coherent Diffraction Imaging. Appl. Phys. Lett. 2018, 113 (20), 203101. 
(76) Hofmann, F.; Tarleton, E.; Harder, R. J.; Phillips, N. W.; Ma, P. W.; Clark, J. N.; Robinson, I. K.; Abbey, B.; Liu, W.; Beck, C. E. 3D Lattice Distortions and Defect Structures in Ion-Implanted NanoCrystals. Sci. Rep. 2017, 7, 45993.

(77) Williams, G. J.; Pfeifer, M. A.; Vartanyants, I. A.; Robinson, I. K. Internal Structure in Small Au Crystals Resolved by ThreeDimensional Inversion of Coherent X-Ray Diffraction. Phys. Rev. B: Condens. Matter Mater. Phys. 2006, 73 (9), 094112.

(78) Kim, J. W.; Manna, S.; Dietze, S. H.; Ulvestad, A.; Harder, R.; Fohtung, E.; Fullerton, E. E.; Shpyrko, O. G. Curvature-Induced and Thermal Strain in Polyhedral Gold Nanocrystals. Appl. Phys. Lett. 2014, 105 (17), 173108.

(79) Clark, J. N.; Beitra, L.; Xiong, G.; Fritz, D. M.; Lemke, H. T.; Zhu, D.; Chollet, M.; Williams, G. J.; Messerschmidt, M. M.; Abbey, B.; Harder, R. J.; Korsunsky, A. M.; Wark, J. S.; Reis, D. A.; Robinson, I. K. Imaging Transient Melting of a Nanocrystal Using an X-Ray Laser. Proc. Natl. Acad. Sci. U. S. A. 2015, 112 (24), 7444-7448.

(80) Xiong, G.; Clark, J. N.; Nicklin, C.; Rawle, J.; Robinson, I. K. Atomic Diffusion within Individual Gold Nanocrystal. Sci. Rep. 2015, 4,6765 .

(81) Newton, M. C.; Shi, X.; Wagner, U.; Rau, C. Coherent Diffraction Imaging of a Progressively Deformed Nanocrystal. Phys. Rev. Mater. 2019, 3 (4), 043803.

(82) Yang, D.; Phillips, N. W.; Song, K.; Harder, R. J.; Cha, W.; Hofmann, F. Annealing of Focused Ion Beam Damage in Gold Microcrystals: An in Situ Bragg Coherent X-Ray Diffraction Imaging Study. J. Synchrotron Radiat. 2021, 28 (2), 550-565.

(83) Watari, M.; McKendry, R. A.; Vögtli, M.; Aeppli, G.; Soh, Y. A.; Shi, X.; Xiong, G.; Huang, X.; Harder, R.; Robinson, I. K. Differential Stress Induced by Thiol Adsorption on Facetted Nanocrystals. Nat. Mater. 2011, 10 (11), 862-866.

(84) Clark, J. N.; Beitra, L.; Xiong, G.; Higginbotham, A.; Fritz, D. M.; Lemke, H. T.; Zhu, D.; Chollet, M.; Williams, G. J.; Messerschmidt, M.; Abbey, B.; Harder, R. J.; Korsunsky, A. M.; Wark, J. S.; Robinson, I. K. Ultrafast Three-Dimensional Imaging of Lattice Dynamics in Individual Gold Nanocrystals. Science (Washington, DC, U. S.) 2013, 341 (6141), 56-59.

(85) Yau, A.; Harder, R. J.; Kanan, M. W.; Ulvestad, A. Imaging the Hydrogen Absorption Dynamics of Individual Grains in Polycrystalline Palladium Thin Films in 3D. ACS Nano 2017, 11 (11), 1094510954.

(86) Ulvestad, A.; Welland, M. J.; Cha, W.; Liu, Y.; Kim, J. W.; Harder, R.; Maxey, E.; Clark, J. N.; Highland, M. J.; You, H.; Zapol, P.; Hruszkewycz, S. O.; Stephenson, G. B. Three-Dimensional Imaging of Dislocation Dynamics during the Hydriding Phase Transformation. Nat. Mater. 2017, 16 (5), 565-571.

(87) Huang, X.; Yang, W.; Harder, R.; Sun, Y.; Lu, M.; Chu, Y. S.; Robinson, I. K.; Mao, H. K. Deformation Twinning of a Silver Nanocrystal under High Pressure. Nano Lett. 2015, 15 (11), 76447649.

(88) Harder, R.; Liang, M.; Sun, Y.; Xia, Y.; Robinson, I. K. Imaging of Complex Density in Silver Nanocubes by Coherent X-ray Diffraction. New J. Phys. 2010, 12, 035019.

(89) Liu, Y.; Lopes, P. P.; Cha, W.; Harder, R.; Maser, J.; Maxey, E.; Highland, M. J.; Markovic, N. M.; Hruszkewycz, S. O.; Stephenson, G. B.; You, H.; Ulvestad, A. Stability Limits and Defect Dynamics in Ag Nanoparticles Probed by Bragg Coherent Diffractive Imaging. Nano Lett. 2017, 17 (3), 1595-1601.

(90) Pedersen, A. F.; Chamard, V.; Detlefs, C.; Zhou, T.; Carbone, D.; Poulsen, H. F. X-ray Coherent Diffraction Imaging with an Objective Lens: Towards Three-Dimensional Mapping of Thick Polycrystals. Phys. Rev. Res. 2020, 2, 033031.

(91) Richard, M. I.; Fernández, S.; Eymery, J.; Hofmann, J. P.; Gao, L.; Carnis, J.; Labat, S.; Favre-Nicolin, V.; Hensen, E. J. M.; Thomas, O.; Schülli, T. U.; Leake, S. J. Crystallographic Orientation of Facets and Planar Defects in Functional Nanostructures Elucidated by NanoFocused Coherent Diffractive X-Ray Imaging. Nanoscale 2018, 10 (10), 4833-4840.
(92) Fernández, S.; Gao, L.; Hofmann, J. P.; Carnis, J.; Labat, S.; Chahine, G. A.; Van Hoof, A. J. F.; Verhoeven, M. W. G. M.; Schülli, T. U.; Hensen, E. J. M.; Thomas, O.; Richard, M. I. In Situ Structural Evolution of Single Particle Model Catalysts under Ambient Pressure Reaction Conditions. Nanoscale 2019, 11 (1), 331-338.

(93) Shi, X.; Harder, R.; Liu, Z.; Shpyrko, O.; Fullerton, E.; Kiefer, B.; Fohtung, E. Nanoscale Mapping of Heterogeneous Strain and Defects in Individual Magnetic Nanocrystals. Crystals 2020, 10 (8), 658.

(94) Kim, J. W.; Manna, S.; Harder, R.; Wingert, J.; Fullerton, E. E.; Shpyrko, O. G. Bragg Coherent Diffractive Imaging of Ferromagnetic Nickel Nanoparticles. J. Appl. Phys. 2018, 123 (20), 204302.

(95) Kim, J. W.; Ulvestad, A.; Manna, S.; Harder, R.; Fullerton, E. E.; Shpyrko, O. G. 3D Bragg Coherent Diffractive Imaging of FiveFold Multiply Twinned Gold Nanoparticle. Nanoscale 2017, 9 (35), 13153-13158.

(96) Maqbool, M. S.; Hoxley, D.; Phillips, N. W.; Coughlan, H. D.; Darmanin, C.; Johnson, B. C.; Harder, R.; Clark, J. N.; Balaur, E.; Abbey, B. Nanoscale Mapping of the Three-Dimensional Deformation Field within Commercial Nanodiamonds. Int. J. Nanotechnol. 2017, 14, 251-264.

(97) Hruszkewycz, S. O.; Cha, W.; Andrich, P.; Anderson, C. P.; Ulvestad, A.; Harder, R.; Fuoss, P. H.; Awschalom, D. D.; Heremans, F. J. In Situ Study of Annealing-Induced Strain Relaxation in Diamond Nanoparticles Using Bragg Coherent Diffraction Imaging. APL Mater. 2017, 5 (2), 026105

(98) Takahashi, Y.; Suzuki, A.; Furutaku, S.; Yamauchi, K.; Kohmura, Y.; Ishikawa, T. Bragg X-ray Ptychography of a Silicon Crystal: Visualization of the Dislocation Strain Field and the Production of a Vortex Beam. Phys. Rev. B: Condens. Matter Mater. Phys. 2013, 87 (12), 121201.

(99) Godard, P.; Carbone, G.; Allain, M.; Mastropietro, F.; Chen, G.; Capello, L.; Diaz, A.; Metzger, T. H.; Stangl, J.; Chamard, V. Three-Dimensional High-Resolution Quantitative Microscopy of Extended Crystals. Nat. Commun. 2011, 2 (1), 568.

(100) Tanaka, Y.; Ito, K.; Newton, M.; Nakatani, T.; Onitsuka, R.; Takahashi, I.; Sato, T.; Togashi, T.; Yabashi, M.; Shimada, K.; Tokuda, K.; Kawaguchi, T.; Ichitsubo, T.; Matsubara, E.; Nishino, Y. Time-Resolved Bragg Coherent X-ray Diffraction Study of Ultrafast Lattice Dynamics in Nano-Sized Thin Crystal by Using X-ray Free Electron Laser. J. Ceram. Soc. Jpn. 2013, 121 (1411), 283-286.

(101) Jacques, V. L. R.; Ravy, S.; Le Bolloc'H, D.; Pinsolle, E.; Sauvage-Simkin, M.; Livet, F. Bulk Dislocation Core Dissociation Probed by Coherent X Rays in Silicon. Phys. Rev. Lett. 2011, 106 (6), 065502.

(102) Newton, M. C.; Parsons, A.; Wagner, U.; Rau, C. Coherent XRay Diffraction Imaging of Photo-Induced Structural Changes in $\mathrm{BiFeO}_{3}$ Nanocrystals. New J. Phys. 2016, 18 (9), 093003.

(103) Maddali, S.; Allain, M.; Cha, W.; Harder, R.; Park, J. S.; Kenesei, P.; Almer, J.; Nashed, Y.; Hruszkewycz, S. O. Phase Retrieval for Bragg Coherent Diffraction Imaging at High X-Ray Energies. Phys. Rev. A: At., Mol., Opt. Phys. 2019, 99 (5), 53838.

(104) Hofmann, F.; Harder, R. J.; Liu, W.; Liu, Y.; Robinson, I. K.; Zayachuk, Y. Glancing-Incidence Focussed Ion Beam Milling: A Coherent X-Ray Diffraction Study of 3D Nano-Scale Lattice Strains and Crystal Defects. Acta Mater. 2018, 154, 113-123.

(105) Choi, S.; Chung, M.; Kim, D.; Kim, S.; Yun, K.; Cha, W.; Harder, R.; Kawaguchi, T.; Liu, Y.; Ulvestad, A.; You, H.; Song, M. K.; Kim, H. In Situ Strain Evolution on Pt Nanoparticles during Hydrogen Peroxide Decomposition. Nano Lett. 2020, 20 (12), 8541-8548.

(106) Estandarte, A. K. C.; Lynch, C. M.; Monteforte, M.; Rawle, J.; Nicklin, C.; Robinson, I. Bragg Coherent Diffraction Imaging of Iron Diffusion into Gold Nanocrystals. New J. Phys. 2018, 20 (11), 113026.

(107) Yang, W.; Huang, X.; Harder, R.; Clark, J. N.; Robinson, I. K.; Mao, H. K. Coherent Diffraction Imaging of Nanoscale Strain Evolution in a Single Crystal under High Pressure. Nat. Commun. 2013, 4, 1680. 
(108) Ulvestad, A.; Clark, J. N.; Harder, R.; Robinson, I. K.; Shpyrko, O. G. 3D Imaging of Twin Domain Defects in Gold Nanoparticles. Nano Lett. 2015, 15 (6), 4066-4070.

(109) Dupraz, M.; Beutier, G.; Cornelius, T. W.; Parry, G.; Ren, Z.; Labat, S.; Richard, M. I.; Chahine, G. A.; Kovalenko, O.; De Boissieu, M.; Rabkin, E.; Verdier, M.; Thomas, O. 3D Imaging of a Dislocation Loop at the Onset of Plasticity in an Indented Nanocrystal. Nano Lett. 2017, 17 (11), 6696-6701.

(110) Lauraux, F.; Cornelius, T. W.; Labat, S.; Richard, M. I.; Leake, S. J.; Zhou, T.; Kovalenko, O.; Rabkin, E.; Schülli, T. U.; Thomas, O. Multi-Wavelength Bragg Coherent X-Ray Diffraction Imaging of $\mathrm{Au}$ Particles. J. Appl. Crystallogr. 2020, 53 (2011), 170-177.

(111) Cha, W.; Song, S.; Jeong, N. C.; Harder, R.; Yoon, K. B.; Robinson, L. K.; Kim, H. Exploration of Crystal Strains Using Coherent X-Ray Diffraction. New J. Phys. 2010, 12, 035022.

(112) Cha, W.; Jeong, N. C.; Song, S.; Park, H. J.; Thanh Pham, T. C.; Harder, R.; Lim, B.; Xiong, G.; Ahn, D.; McNulty, I.; Kim, J.; Yoon, K. B.; Robinson, I. K.; Kim, H. Core-Shell Strain Structure of Zeolite Microcrystals. Nat. Mater. 2013, 12 (8), 729-734.

(113) Hejral, U.; Franz, D.; Volkov, S.; Francoual, S.; Strempfer, J.; Stierle, A. Identification of a Catalytically Highly Active Surface Phase for CO Oxidation over PtRh Nanoparticles under Operando Reaction Conditions. Phys. Rev. Lett. 2018, 120 (12), 126101.

(114) Kawaguchi, T.; Keller, T. F.; Runge, H.; Gelisio, L.; Seitz, C.; Kim, Y. Y.; Maxey, E. R.; Cha, W.; Ulvestad, A.; Hruszkewycz, S. O.; Harder, R.; Vartanyants, I. A.; Stierle, A.; You, H. Gas-Induced Segregation in Pt-Rh Alloy Nanoparticles Observed by in Situ Bragg Coherent Diffraction Imaging. Phys. Rev. Lett. 2019, 123 (24), 246001.

(115) Rochet, A.; Suzana, A. F.; Passos, A. R.; Kalile, T.; Berenguer, F.; Santilli, C. V.; Pulcinelli, S. H.; Meneau, F. In Situ Reactor to Image Catalysts at Work in Three-Dimensions by Bragg Coherent Xray Diffraction. Catal. Today 2019, 336, 169-173.

(116) Suzana, A. F.; Rochet, A.; Passos, A. R.; Castro Zerba, J. P.; Polo, C. C.; Santilli, C. V.; Pulcinelli, S. H.; Berenguer, F.; Harder, R.; Maxey, E.; Meneau, F. In Situ Three-Dimensional Imaging of Strain in Gold Nanocrystals during Catalytic Oxidation. Nanoscale Adv. 2019, 1 (8), 3009-3014.

(117) Kawaguchi, T.; Cha, W.; Latyshev, V.; Vorobiov, S.; Komanicky, V.; You, H. Study of the Internal Compositions of Binary Alloy Pd-Rh Nanoparticles by Using Bragg Coherent Diffraction Imaging. J. Korean Phys. Soc. 2019, 75 (7), 528-533.

(118) Kim, D.; Chung, M.; Kim, S.; Yun, K.; Cha, W.; Harder, R.; Kim, H. Defect Dynamics at a Single Pt Nanoparticle during Catalytic Oxidation. Nano Lett. 2019, 19 (8), 5044-5052.

(119) Abuin, M.; Kim, Y. Y.; Runge, H.; Kulkarni, S.; Maier, S.; Dzhigaev, D.; Lazarev, S.; Gelisio, L.; Seitz, C.; Richard, M. I.; Zhou, T.; Vonk, V.; Keller, T. F.; Vartanyants, I. A.; Stierle, A. Coherent XRay Imaging of CO-Adsorption-Induced Structural Changes in $\mathrm{Pt}$ Nanoparticles: Implications for Catalysis. ACS Appl. Nano Mater. 2019, 2 (8), 4818-4824.

(120) Passos, A. R.; Rochet, A.; Manente, L. M.; Suzana, A. F.; Harder, R.; Cha, W.; Meneau, F. Three-Dimensional Strain Dynamics Govern the Hysteresis in Heterogeneous Catalysis. Nat. Commun. 2020, 11 (1), 4733.

(121) Hua, W.; Wang, S.; Knapp, M.; Leake, S. J.; Senyshyn, A.; Richter, C.; Yavuz, M.; Binder, J. R.; Grey, C. P.; Ehrenberg, H.; Indris, S.; Schwarz, B. Structural Insights into the Formation and Voltage Degradation of Lithium- and Manganese-Rich Layered Oxides. Nat. Commun. 2019, 10 (1), 5365.

(122) Singer, A.; Ulvestad, A.; Cho, H. M.; Kim, J. W.; Maser, J.; Harder, R.; Meng, Y. S.; Shpyrko, O. G. Nonequilibrium Structural Dynamics of Nanoparticles in $\mathrm{LiNi}_{1 / 2} \mathrm{Mn}_{3 / 2} \mathrm{O}_{4}$ cathode under Operando Conditions. Nano Lett. 2014, 14 (9), 5295-5300.

(123) Singer, A.; Zhang, M.; Hy, S.; Cela, D.; Fang, C.; Wynn, T. A.; Qiu, B.; Xia, Y.; Liu, Z.; Ulvestad, A.; Hua, N.; Wingert, J.; Liu, H.; Sprung, M.; Zozulya, A. V.; Maxey, E.; Harder, R.; Meng, Y. S.; Shpyrko, O. G. Nucleation of Dislocations and Their Dynamics in
Layered Oxide Cathode Materials during Battery Charging. Nat. Energy 2018, 3 (8), 641-647.

(124) Ulvestad, A.; Cho, H. M.; Harder, R.; Kim, J. W.; Dietze, S. H.; Fohtung, E.; Meng, Y. S.; Shpyrko, O. G. Nanoscale Strain Mapping in Battery Nanostructures. Appl. Phys. Lett. 2014, 104 (7), 073108.

(125) Ulvestad, A.; Clark, J. N.; Singer, A.; Vine, D.; Cho, H. M.; Harder, R.; Meng, Y. S.; Shpyrko, O. G. In Situ Strain Evolution during a Disconnection Event in a Battery Nanoparticle. Phys. Chem. Chem. Phys. 2015, 17 (16), 10551-10555.

(126) Ulvestad, U.; Singer, A.; Clark, J. N.; Cho, H. M.; Kim, J. W.; Harder, R.; Maser, J.; Meng, Y. S.; Shpyrko, O. G. Topological Defect Dynamics in Operando Battery Nanoparticles. Science (Washington, DC, U. S.) 2015, 348 (6241), 1344-1347.

(127) Ulvestad, A.; Singer, A.; Cho, H. M.; Clark, J. N.; Harder, R.; Maser, J.; Meng, Y. S.; Shpyrko, O. G. Single Particle Nanomechanics in Operando Batteries via Lensless Strain Mapping. Nano Lett. 2014, 14 (9), 5123-5127.

(128) Harder, R.; Robinson, I. K. Coherent X-Ray Diffraction Imaging of Morphology and Strain in Nanomaterials. JOM 2013, 65 (9), 1202-1207.

(129) Diao, J.; Cherukara, M.; Harder, R.; Huang, X.; Zhang, F.; Chen, B.; Ulvestad, A.; Song, S.; Zhu, D.; Keen, D.; Robinson, I. Unusual Breathing Behavior of Optically Excited Barium Titanate Nanocrystals. Crystals 2020, 10 (5), 365.

(130) Karpov, D.; Liu, Z.; Rolo, T. D. S.; Harder, R.; Balachandran, P. V.; Xue, D.; Lookman, T.; Fohtung, E. Three-Dimensional Imaging of Vortex Structure in a Ferroelectric Nanoparticle Driven by an Electric Field. Nat. Commun. 2017, 8 (1), 280.

(131) Liu, Z.; Schold, E.; Karpov, D.; Harder, R.; Lookman, T.; Fohtung, E. Needle-Like Ferroelastic Domains in Individual Ferroelectric Nanoparticles. Adv. Electron. Mater. 2020, 6 (5), 1901300.

(132) Davtyan, A.; Favre-Nicolin, V.; Lewis, R. B.; KüPers, H.; Geelhaar, L.; Kriegner, D.; Bahrami, D.; Al-Hassan, A.; Chahine, G.; Loffeld, O.; Pietsch, U. Coherent X-Ray Diffraction Imaging Meets Ptychography to Study Core-Shell-Shell Nanowires. MRS Adv. 2018, 3 (39), 2317-2322.

(133) Hill, M. O.; Calvo-Almazan, I.; Allain, M.; Holt, M. V.; Ulvestad, A.; Treu, J.; Koblmüller, G.; Huang, C.; Huang, X.; Yan, H.; Nazaretski, E.; Chu, Y. S.; Stephenson, G. B.; Chamard, V.; Lauhon, L. J.; Hruszkewycz, S. O. Measuring Three-Dimensional Strain and Structural Defects in a Single InGaAs Nanowire Using Coherent XRay Multiangle Bragg Projection Ptychography. Nano Lett. 2018, 18 (2), 811-819.

(134) Dzhigaev, D.; Shabalin, A.; Stankevič, T.; Lorenz, U.; Kurta, R. P.; Seiboth, F.; Wallentin, J.; Singer, A.; Lazarev, S.; Yefanov, O. M.; Borgström, M.; Strikhanov, M. N.; Samuelson, L.; Falkenberg, G.; Schroer, C. G.; Mikkelsen, A.; Feidenhans'l, L. R.; Vartanyants, I. A. Bragg Coherent X-ray Diffractive Imaging of a Single Indium Phosphide Nanowire. J. Opt. 2016, 18 (6), 064007.

(135) Chamard, V.; Diaz, A.; Stangl, J.; Labat, S. Stuctural Investigation of InAs Nanowires with Coherent X-Rays. J. Strain Anal. Eng. Des. 2009, 44 (7), 533-542.

(136) Li, N.; Labat, S.; Leake, S. J.; Dupraz, M.; Carnis, J.; Cornelius, T. W.; Beutier, G.; Verdier, M.; Favre-Nicolin, V.; Schülli, T. U.; Thomas, O.; Eymery, J.; Richard, M. I. Mapping Inversion Domain Boundaries along Single GaN Wires with Bragg Coherent X-Ray Imaging. ACS Nano 2020, 14, 10305-10312.

(137) Labat, S.; Richard, M. I.; Dupraz, M.; Gailhanou, M.; Beutier, G.; Verdier, M.; Mastropietro, F.; Cornelius, T. W.; Schülli, T. U.; Eymery, J.; Thomas, O. Inversion Domain Boundaries in GaN Wires Revealed by Coherent Bragg Imaging. ACS Nano 2015, 9 (9), 92109216.

(138) Haag, S. T.; Richard, M. I.; Favre-Nicolin, V.; Welzel, U.; Jeurgens, L. P. H.; Ravy, S.; Richter, G.; Mittemeijer, E. J.; Thomas, O. In Situ Coherent X-Ray Diffraction of Isolated Core-Shell Nanowires. Thin Solid Films 2013, 530, 113-119.

(139) Davtyan, A.; Krause, T.; Kriegner, D.; Al-Hassan, A.; Bahrami, D.; Mostafavi Kashani, S. M.; Lewis, R. B.; KüPers, H.; Tahraoui, A.; 
Geelhaar, L.; Hanke, M.; Leake, S. J.; Loffeld, O.; Pietsch, U. Threefold Rotational Symmetry in Hexagonally Shaped Core-Shell (In,Ga)As/GaAs Nanowires Revealed by Coherent X-Ray Diffraction Imaging. J. Appl. Crystallogr. 2017, 50 (3), 673-680.

(140) Diaz, A.; Mocuta, C.; Stangl, J.; Mandl, B.; David, C.; VilaComamala, J.; Chamard, V.; Metzger, T. H.; Bauer, G. Coherent Diffraction Imaging of a Single Epitaxial InAs Nanowire Using a Focused X-ray Beam. Phys. Rev. B: Condens. Matter Mater. Phys. 2009, 79 (12), 125324.

(141) Minkevich, A. A.; Fohtung, E.; Slobodskyy, T.; Riotte, M.; Grigoriev, D.; Metzger, T.; Irvine, A. C.; Novák, V.; Holý, V.; Baumbach, T. Strain Field in (Ga,Mn)As/GaAs Periodic Wires Revealed by Coherent X-ray Diffraction. EPL 2011, 94 (6), 66001.

(142) Shi, X.; Clark, J. N.; Xiong, G.; Huang, X.; Harder, R.; Robinson, I. K. Mechanical Breakdown of Bent Silicon Nanowires Imaged by Coherent X-Ray Diffraction. New J. Phys. 2013, 15, 123007.

(143) Clark, J. N.; Ihli, J.; Schenk, A. S.; Kim, Y. Y.; Kulak, A. N.; Campbell, J. M.; Nisbet, G.; Meldrum, F. C.; Robinson, I. K. ThreeDimensional Imaging of Dislocation Propagation during Crystal Growth and Dissolution. Nat. Mater. 2015, 14 (8), 780-784.

(144) Yuan, K.; Lee, S. S.; Cha, W.; Ulvestad, A.; Kim, H.; Abdilla, B.; Sturchio, N. C.; Fenter, P. Oxidation Induced Strain and Defects in Magnetite Crystals. Nat. Commun. 2019, 10 (1), 703.

(145) Aranda, M. A. G.; Berenguer, F.; Bean, R. J.; Shi, X.; Xiong, G.; Collins, S. P.; Nave, C.; Robinson, I. K. Coherent X-Ray Diffraction Investigation of Twinned Microcrystals. J. Synchrotron Radiat. 2010, 17 (6), 751-760.

(146) Ihli, J.; Clark, J. N.; Côté, A. S.; Kim, Y. Y.; Schenk, A. S.; Kulak, A. N.; Comyn, T. P.; Chammas, O.; Harder, R. J.; Duffy, D. M.; Robinson, I. K.; Meldrum, F. C. Strain-Relief by Single Dislocation Loops in Calcite Crystals Grown on Self-Assembled Monolayers. Nat. Commun. 2016, 7, 11878.

(147) Ihli, J.; Clark, J. N.; Kanwal, N.; Kim, Y. Y.; Holden, M. A.; Harder, R. J.; Tang, C. C.; Ashbrook, S. E.; Robinson, I. K.; Meldrum, F. C. Visualization of the Effect of Additives on the Nanostructures of Individual Bio-Inspired Calcite Crystals. Chem. Sci. 2019, 10 (4), $1176-1185$.

(148) Robinson, I.; Assefa, T. A.; Cao, Y.; Gu, G.; Harder, R.; Maxey, E.; Dean, M. P. M. Domain Texture of the Orthorhombic Phase of $\mathrm{La}_{2-\mathrm{x}} \mathrm{Ba}_{\mathrm{x}} \mathrm{CuO}_{4}$. J. Supercond. Novel Magn. 2020, 33 (1), 99106.

(149) Diao, J.; Chen, B.; Luo, Q.; Lin, W.; Liu, X.; Shen, J.; Robinson, I. Nucleation of Fractal Nanocrystallites upon Annealing of Fe-Based Metallic Glass. J. Mater. Res. 2017, 32, 1880-1887.

(150) Chen, B.; Diao, J.; Luo, Q.; Rawle, J.; Liu, X.; Nicklin, C.; Shen, J.; Robinson, I. In Situ Investigation of Crystallization and Structural Evolution of a Metallic Glass in Three Dimensions at Nano-Scale. Mater. Des. 2020, 190, 108551.

(151) Chen-Wiegart, Y. C. K.; Harder, R.; Dunand, D. C.; McNulty, I. Evolution of Dealloying Induced Strain in Nanoporous Gold Crystals. Nanoscale 2017, 9 (17), 5686-5693.

(152) Cha, W.; Liu, Y.; You, H.; Stephenson, G. B.; Ulvestad, A. Dealloying in Individual Nanoparticles and Thin Film Grains: A Bragg Coherent Diffractive Imaging Study. Adv. Funct. Mater. 2017, 27 (25), 1700331.

(153) Chamard, V.; Dollé, M.; Baldinozzi, G.; Livet, F.; De Boissieu, M.; Labat, S.; Picca, F.; Mocuta, C.; Donnadieu, P.; Metzger, T. H. Strain Analysis by Inversion of Coherent Bragg X-Ray Diffraction Intensity: The Illumination Problem. J. Mod. Opt. 2010, 57 (9), 816825 .

(154) Newton, M. C.; Leake, S. J.; Harder, R.; Robinson, I. K. Three-Dimensional Imaging of Strain in a Single ZnO Nanorod. Nat. Mater. 2010, 9 (2), 120-124.

(155) Huang, X.; Harder, R.; Leake, S.; Clark, J.; Robinson, I. ThreeDimensional Bragg Coherent Diffraction Imaging of an Extended ZnO Crystal. J. Appl. Crystallogr. 2012, 45 (4), 778-784.

(156) Xiong, G.; Huang, X.; Leake, S.; Newton, M. C.; Harder, R.; Robinson, I. K. Coherent X-Ray Diffraction Imaging of $\mathrm{ZnO}$
Nanostructures under Confined Illumination. New J. Phys. 2011, 13, 033006.

(157) Ulvestad, A.; Cherukara, M. J.; Harder, R.; Cha, W.; Robinson, I. K.; Soog, S.; Nelson, S.; Zhu, D.; Stephenson, G. B.; Heinonen, O.; Jokisaari, A. Bragg Coherent Diffractive Imaging of Zinc Oxide Acoustic Phonons at Picosecond Timescales. Sci. Rep. 2017, 7 (1), 9823.

(158) Leake, S. J.; Harder, R.; Robinson, I. K. Coherent Diffractive Imaging of Solid State Reactions in Zinc Oxide Crystals. New J. Phys. 2011, 13, 113009.

(159) Coughlan, H. D.; Darmanin, C.; Kirkwood, H. J.; Phillips, N. W.; Hoxley, D.; Clark, J. N.; Vine, D. J.; Hofmann, F.; Harder, R. J.; Maxey, E.; Abbey, B. Bragg Coherent Diffraction Imaging and Metrics for Radiation Damage in Protein Micro-Crystallography. J. Synchrotron Radiat. 2017, 24 (1), 83-94.

(160) Coughlan, H. D.; Darmanin, C.; Kirkwood, H. J.; Phillips, N. W.; Hoxley, D.; Clark, J. N.; Harder, R. J.; Maxey, E.; Abbey, B. Three-Dimensional Reconstruction of the Size and Shape of Protein Microcrystals Using Bragg Coherent Diffractive Imaging. J. Opt. 2016, 18 (5), 054003.

(161) Coughlan, H. D.; Darmanin, C.; Phillips, N. W.; Hofmann, F.; Clark, J. N.; Harder, R. J.; Vine, D. J.; Abbey, B. Radiation Damage in a Micron-Sized Protein Crystal Studied via Reciprocal Space Mapping and Bragg Coherent Diffractive Imaging. Struct. Dyn. 2015, 2 (4), 041704 .

(162) Vaxelaire, N; Proudhon, H; Labat, S; Kirchlechner, C; Keckes, J; Jacques, V; Ravy, S; Forest, S; Thomas, O Methodology for Studying Strain Inhomogeneities in Polycrystalline Thin Films during in Situ Thermal Loading Using Coherent X-Ray Diffraction. New J. Phys. 2010, 12, 035018.

(163) Vaxelaire, N.; Labat, S.; Cornelius, T. W.; Kirchlechner, C.; Keckes, J.; Schulli, T.; Thomas, O. New Insights into Single-Grain Mechanical Behavior from Temperature-Dependent 3D Coherent XRay Diffraction. Acta Mater. 2014, 78, 46-55.

(164) Xiong, G.; Moutanabbir, O.; Huang, X.; Paknejad, S. A.; Shi, X.; Harder, R.; Reiche, M.; Robinson, I. K. Elastic Relaxation in an Ultrathin Strained Silicon-on-Insulator Structure. Appl. Phys. Lett. 2011, 99 (11), 114103.

(165) Phillips, N. W.; Yu, H.; Das, S.; Yang, D.; Mizohata, K.; Liu, W.; Xu, R.; Harder, R. J.; Hofmann, F. Nanoscale Lattice Strains in Self-Ion Implanted Tungsten. Acta Mater. 2020, 195, 219-228.

(166) Hruszkewycz, S. O.; Allain, M.; Holt, M. V.; Murray, C. E.; Holt, J. R.; Fuoss, P. H.; Chamard, V. High-Resolution ThreeDimensional Structural Microscopy by Single-Angle Bragg Ptychography. Nat. Mater. 2017, 16 (2), 244-251.

(167) Li, L.; Xie, Y.; Maxey, E.; Harder, R. Methods for Operando Coherent X-Ray Diffraction of Battery Materials at the Advanced Photon Source. J. Synchrotron Radiat. 2019, 26 (1), 220-229.

(168) Wolf, M.; May, B. M.; Cabana, J. Visualization of Electrochemical Reactions in Battery Materials with X-Ray Microscopy and Mapping. Chem. Mater. 2017, 29 (8), 3347-3362.

(169) Wang, L.; Wang, J.; Zuo, P. Probing Battery Electrochemistry with in Operando Synchrotron X-Ray Imaging Techniques. Small Methods 2018, 2 (8), 1700293.

(170) Chen, Q.; Ding, Y.; Chen, M. Nanoporous Metal by Dealloying for Electrochemical Energy Conversion and Storage. MRS Bull. 2018, 43 (1), 43-48.

(171) Erlebacher, J.; Seshadri, R. Hard Materials with Tunable Porosity. MRS Bull. 2009, 34 (8), 561-568.

(172) Pan, L.; Ott, S.; Dionigi, F.; Strasser, P. Current Challenges Related to the Deployment of Shape-Controlled Pt Alloy Oxygen Reduction Reaction Nanocatalysts into Low Pt-Loaded Cathode Layers of Proton Exchange Membrane Fuel Cells. Curr. Opin. Electrochem. 2019, 18, 61-71.

(173) Yu, Y.; Gu, L.; Lang, X.; Zhu, C.; Fujita, T.; Chen, M.; Maier, J. Li Storage in 3D Nanoporous Au-Supported Nanocrystalline Tin. Adv. Mater. 2011, 23 (21), 2443-2447. 
(174) Lang, X.; Hirata, A.; Fujita, T.; Chen, M. Nanoporous Metal/ Oxide Hybrid Electrodes for Electrochemical Supercapacitors. Nat. Nanotechnol. 2011, 6 (4), 232-236.

(175) Gawande, M. B.; Goswami, A.; Asefa, T.; Guo, H.; Biradar, A. V.; Peng, D. L.; Zboril, R.; Varma, R. S. Core-Shell Nanoparticles: Synthesis and Applications in Catalysis and Electrocatalysis. Chem. Soc. Rev. 2015, 44 (21), 7540-7590.

(176) Strasser, P.; Koh, S.; Anniyev, T.; Greeley, J.; More, K.; Yu, C.; Liu, Z.; Kaya, S.; Nordlund, D.; Ogasawara, H.; Toney, M. F.; Nilsson, A. Lattice-Strain Control of the Activity in Dealloyed CoreShell Fuel Cell Catalysts. Nat. Chem. 2010, 2 (6), 454-460.

(177) Eftekhari, A.; Fang, B. Electrochemical Hydrogen Storage: Opportunities for Fuel Storage, Batteries, Fuel Cells, and Supercapacitors. Int. J. Hydrogen Energy 2017, 42 (40), 25143-25165.

(178) Nørskov, J. K.; Studt, F.; Abild-Pedersen, F.; Bligaard, T. Fundamental Concepts in Heterogeneous Catalysis; John Wiley \& Sons: Hoboken, NJ, USA, 2014; DOI: 10.1002/9781118892114.

(179) Mistry, H.; Varela, A. S.; Kühl, S.; Strasser, P.; Cuenya, B. R. Nanostructured Electrocatalysts with Tunable Activity and Selectivity. Nat. Rev. Mater. 2016, 1, 16009.

(180) Shao, M.; Chang, Q.; Dodelet, J. P.; Chenitz, R. Recent Advances in Electrocatalysts for Oxygen Reduction Reaction. Chem. Rev. 2016, 116 (6), 3594-3657.

(181) Yu, W.; Porosoff, M. D.; Chen, J. G. Review of Pt-Based Bimetallic Catalysis: From Model Surfaces to Supported Catalysts. Chem. Rev. 2012, 112 (11), 5780-5817.

(182) Wang, Y. J.; Zhao, N.; Fang, B.; Li, H.; Bi, X. T.; Wang, H. Carbon-Supported Pt-Based Alloy Electrocatalysts for the Oxygen Reduction Reaction in Polymer Electrolyte Membrane Fuel Cells: Particle Size, Shape, and Composition Manipulation and Their Impact to Activity. Chem. Rev. 2015, 115 (9), 3433-3467.

(183) Stephens, I. E. L.; Bondarenko, A. S.; Grønbjerg, U.; Rossmeisl, J.; Chorkendorff, I. Understanding the Electrocatalysis of Oxygen Reduction on Platinum and Its Alloys. Energy Environ. Sci. 2012, 5 (5), 6744-6762.

(184) Luo, M.; Sun, Y.; Wang, L.; Guo, S. Tuning Multimetallic Ordered Intermetallic Nanocrystals for Efficient Energy Electrocatalysis. Adv. Energy Mater. 2017, 7 (11), 1602073.

(185) Mavrikakis, M.; Hammer, B.; Nørskov, J. K. Effect of Strain on the Reactivity of Metal Surfaces. Phys. Rev. Lett. 1998, 81 (13), 28192822.

(186) Wang, L.; Zeng, Z.; Gao, W.; Maxson, T.; Raciti, D.; Giroux, M.; Pan, X.; Wang, C.; Greeley, J. Tunable Intrinsic Strain in TwoDimensional Transition Metal Electrocatalysts. Science 2019, 363 (6429), 870-874.

(187) Luo, M.; Guo, S. Strain-Controlled Electrocatalysis on Multimetallic Nanomaterials. Nat. Rev. Mater. 2017, 2, 17059.

(188) Xia, Z.; Guo, S. Strain Engineering of Metal-Based Nanomaterials for Energy Electrocatalysis. Chem. Soc. Rev. 2019, 48 (12), 3265-3278.

(189) You, B.; Tang, M. T.; Tsai, C.; Abild-Pedersen, F.; Zheng, X.; $\mathrm{Li}, \mathrm{H}$. Enhancing Electrocatalytic Water Splitting by Strain Engineering. Adv. Mater. 2019, 31 (17), 1807001.

(190) Li, M.; Zhao, Z.; Cheng, T.; Fortunelli, A.; Chen, C. Y.; Yu, R.; Zhang, Q.; Gu, L.; Merinov, B. V.; Lin, Z.; Zhu, E.; Yu, T.; Jia, Q.; Guo, J.; Zhang, L.; Goddard, W. A.; Huang, Y.; Duan, X. Ultrafine Jagged Platinum Nanowires Enable Ultrahigh Mass Activity for the Oxygen Reduction Reaction. Science (Washington, DC, U. S.) 2016, 354 (6318), 1414-1419.

(191) Grabow, L.; Xu, Y.; Mavrikakis, M. Lattice Strain Effects on CO Oxidation on Pt(111). Phys. Chem. Chem. Phys. 2006, 8 (29), 3369-3374.

(192) Xu, Y.; Mavrikakis, M. Adsorption and Dissociation of $\mathrm{O}_{2}$ on Gold Surfaces: Effect of Steps and Strain. J. Phys. Chem. B 2003, 107 (35), 9298-9307.

(193) Huang, W. J.; Sun, R.; Tao, J.; Menard, L. D.; Nuzzo, R. G.; Zuo, J. M. Coordination-Dependent Surface Atomic Contraction in Nanocrystals Revealed by Coherent Diffraction. Nat. Mater. 2008, 7 (4), 308-313.
(194) Nørskov, J. K.; Abild-Pedersen, F.; Studt, F.; Bligaard, T. Density Functional Theory in Surface Chemistry and Catalysis. Proc. Natl. Acad. Sci. U. S. A. 2011, 108 (3), 937-943.

(195) Chattot, R.; Le Bacq, O.; Beermann, V.; Kühl, S.; Herranz, J.; Henning, S.; Kühn, L.; Asset, T.; Guétaz, L.; Renou, G.; Drnec, J.; Bordet, P.; Pasturel, A.; Eychmüller, A.; Schmidt, T. J.; Strasser, P.; Dubau, L.; Maillard, F. Surface Distortion as a Unifying Concept and Descriptor in Oxygen Reduction Reaction Electrocatalysis. Nat. Mater. 2018, 17 (9), 827-833.

(196) Dubau, L.; Nelayah, J.; Asset, T.; Chattot, R.; Maillard, F. Implementing Structural Disorder as a Promising Direction for Improving the Stability of PtNi/C Nanoparticles. ACS Catal. 2017, 7 (4), 3072-3081.

(197) Kuo, C. H.; Lamontagne, L. K.; Brodsky, C. N.; Chou, L. Y.; Zhuang, J.; Sneed, B. T.; Sheehan, M. K.; Tsung, C. K. The Effect of Lattice Strain on the Catalytic Properties of Pd Nanocrystals. ChemSusChem 2013, 6 (10), 1993-2000.

(198) Temmel, S. E.; Fabbri, E.; Pergolesi, D.; Lippert, T.; Schmidt, T. J. Investigating the Role of Strain toward the Oxygen Reduction Activity on Model Thin Film Pt Catalysts. ACS Catal. 2016, 6 (11), 7566-7576.

(199) Walsh, M. J.; Yoshida, K.; Pay, M. L.; Gai, P. L.; Boyes, E. D. On the Effect of Atomic Structure on the Activity and Deactivation of Catalytic Gold Nanoparticles. ChemCatChem 2012, 4 (10), 16381644.

(200) Gan, L.; Yu, R.; Luo, J.; Cheng, Z.; Zhu, J. Lattice Strain Distributions in Individual Dealloyed Pt-Fe Catalyst Nanoparticles. J. Phys. Chem. Lett. 2012, 3 (7), 934-938.

(201) Goris, B.; Bals, S.; Van Den Broek, W.; Carbó-Argibay, E.; Gómez-Graña, S.; Liz-Marzán, L. M.; Van Tendeloo, G. Atomic-Scale Determination of Surface Facets in Gold Nanorods. Nat. Mater. 2012, 11 (11), 930-935.

(202) Xu, R.; Chen, C. C.; Wu, L.; Scott, M. C.; Theis, W.; Ophus, C.; Bartels, M.; Yang, Y.; Ramezani-Dakhel, H.; Sawaya, M. R.; Heinz, H.; Marks, L. D.; Ercius, P.; Miao, J. Three-Dimensional Coordinates of Individual Atoms in Materials Revealed by Electron Tomography. Nat. Mater. 2015, 14 (11), 1099-1103.

(203) Miao, J.; Ercius, P.; Billinge, S. J. L. Atomic Electron Tomography: 3D Structures without Crystals. Science 2016, 353 (6306), aaf2157.

(204) Pu, C.; Dai, X.; Shu, Y.; Zhu, M.; Deng, Y.; Jin, Y.; Peng, X. Electrochemically-Stable Ligands Bridge the PhotoluminescenceElectroluminescence Gap of Quantum Dots. Nat. Commun. 2020, 11 (1), 937.

(205) Kash, K.; Bhat, R.; Mahoney, D. D.; Lin, P. S. D.; Scherer, A.; Worlock, J. M.; Van der Gaag, B. P.; Koza, M.; Grabbe, P. StrainInduced Confinement of Carriers to Quantum Wires and Dots within an InGaAs-InP Quantum Well. Appl. Phys. Lett. 1989, 55 (7), 681683.

(206) Kim, J. W.; Ulvestad, A.; Manna, S.; Harder, R.; Fohtung, E.; Singer, A.; Boucheron, L.; Fullerton, E. E.; Shpyrko, O. G. Observation of X-ray Radiation Pressure Effects on Nanocrystals. J. Appl. Phys. 2016, 120 (16), 163102.

(207) Calvo-Almazán, I.; Allain, M.; Maddali, S.; Chamard, V.; Hruszkewycz, S. O. Impact and Mitigation of Angular Uncertainties in Bragg Coherent X-Ray Diffraction Imaging. Sci. Rep. 2019, 9 (1), 6386.

(208) Sanfelici, L.; Cardoso, F. H.; Piton, J. R.; Meyer, B. C.; Polli, J. M.; Miqueles, E. X.; Zambello, F. R.; Westfahl, H. Solutions for the SIRIUS' Beamlines in a Nutshell. AIP Conf. Proc. 2018, 2054, 030033.

(209) Chan, H.; Nashed, Y. S. G.; Kandel, S.; Hruszkewycz, S.; Sankaranarayanan, S.; Harder, R. J.; Cherukara, M. J. Real-Time 3D Nanoscale Coherent Imaging via Physics-Aware Deep Learning. arXiv Preprint (Electrical Engineering and Systems Science: Image and Video Processing), 2020. 2006.09441. https://arxiv.org/abs/2006. 09441 (acessed 2021-03-15). 